\title{
Brain-Derived Neurotrophic Factor and Neuropsychiatric Disorders
}

\author{
Anita E. Autry and Lisa M. Monteggia \\ Department of Psychiatry, University of Texas Southwestern Medical Center, Dallas, Texas
}

Abstract. ........................................................ 239

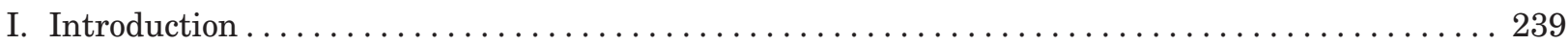

A. Brain-derived neurotrophic factor signaling through tropomyosin-related kinase B

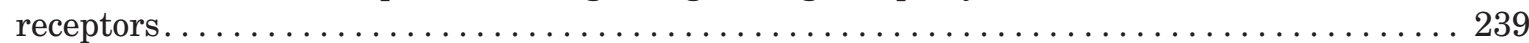

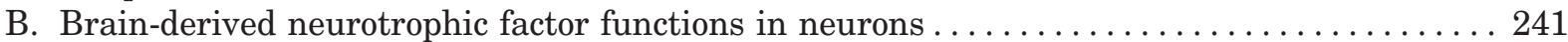

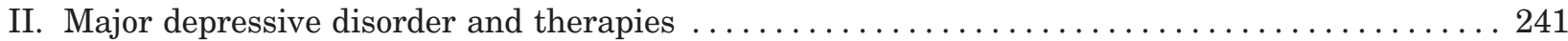

A. Brain-derived neurotrophic factor regulation by major depressive disorder and

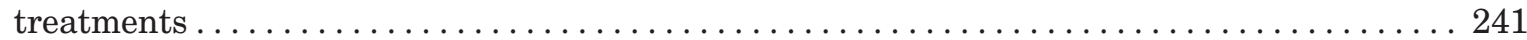

1. Brain-derived neurotrophic factor expression in human patients with depression...... 241

2. Brain-derived neurotrophic factor expression in patients treated with

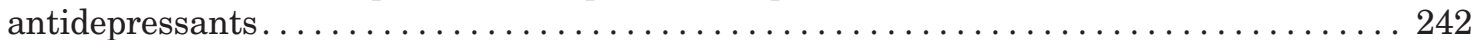

B. Brain-derived neurotrophic factor in behavioral models of depression . . . . . . . . . . 242

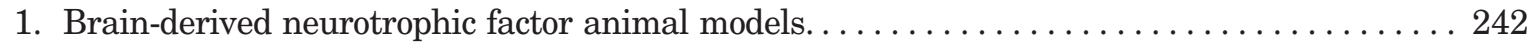

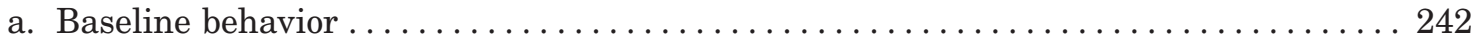

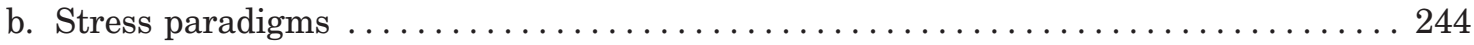

2. Brain-derived neurotrophic factor produces an antidepressant response in animal

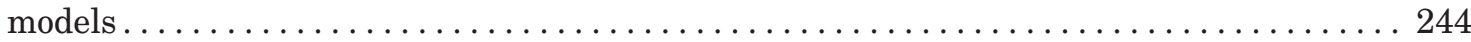

3. Interplay between brain-derived neurotrophic factor and the serotonergic system . . . 244

C. Association of brain-derived neurotrophic factor and neurogenesis in depression and

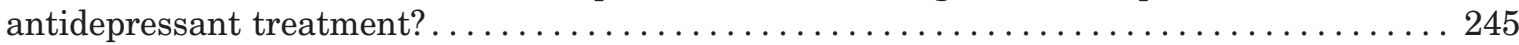

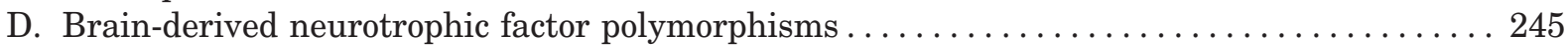

III. Brain-derived neurotrophic factor and other mood-related disorders . . . . . . . . . . . . . 245

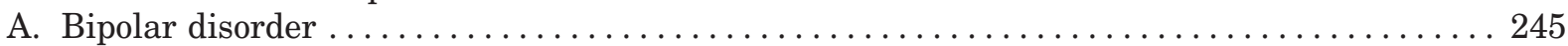

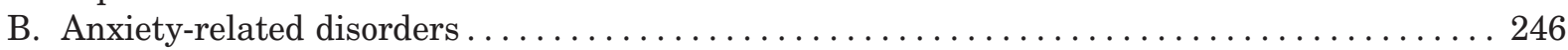

1. Anxiety in brain-derived neurotrophic factor mouse models $\ldots \ldots \ldots \ldots \ldots \ldots \ldots \ldots 246$

2. Brain-derived neurotrophic factor and anxiety in human studies. . . . . . . . . . 246

3. Potential link between brain-derived neurotrophic factor and post-traumatic stress

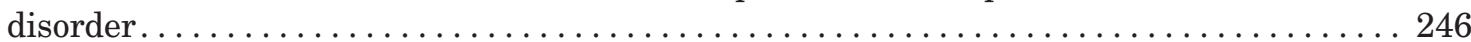

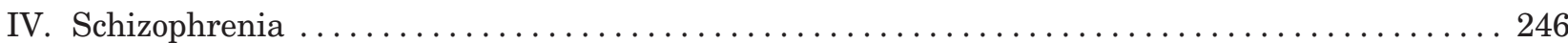

A. Brain-derived neurotrophic factor and schizophrenia $\ldots \ldots \ldots \ldots \ldots \ldots \ldots \ldots \ldots \ldots$

B. Antipsychotic drug effects on brain-derived neurotrophic factor expression . . . . . . . 247

C. Altered brain-derived neurotrophic factor levels in animal models of schizophrenia . . . . . 247

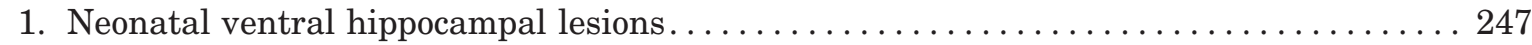

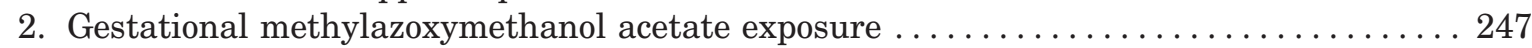

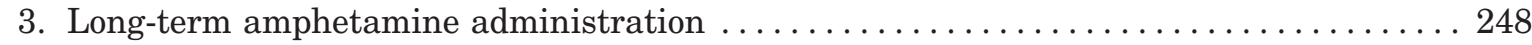

D. Brain-derived neurotrophic factor animal models in schizophrenia-like behaviors . . . . . . 249

1. Brain-derived neurotrophic factor heterozygous mice . . . . . . . . . . . . . . 249

2. Conditional/inducible brain-derived neurotrophic factor deletion mice $\ldots \ldots \ldots \ldots \ldots 249$

E. Brain-derived neurotrophic factor polymorphisms and schizophrenia . . . . . . . . . 249

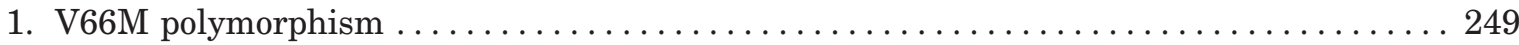

Address correspondence to: Dr. Lisa M. Monteggia, Department of Psychiatry, The University of Texas Southwestern Medical Center, 5323 Harry Hines Blvd, Dallas, TX 75390-9070. E-mail: lisa.monteggia@utsouthwestern.edu

This article is available online at http://pharmrev.aspetjournals.org.

http://dx.doi.org/10.1124/pr.111.005108. 


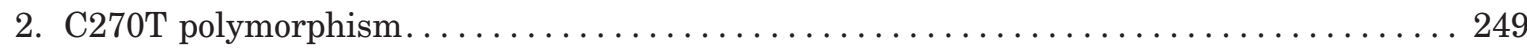

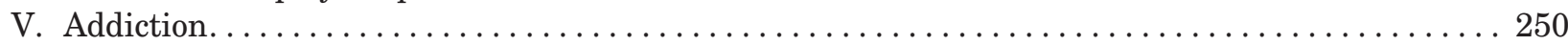

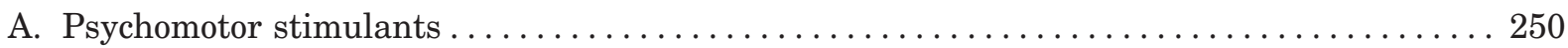

1. Psychomotor stimulants alter brain-derived neurotrophic factor levels. . . . . . . 250

2. Brain-derived neurotrophic factor infusions alter addiction-related behaviors $\ldots \ldots \ldots 250$

3. Brain-derived neurotrophic factor animal models show altered addiction-related

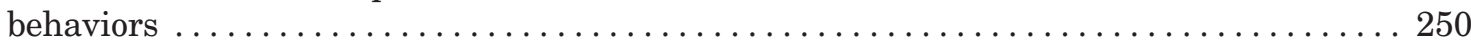

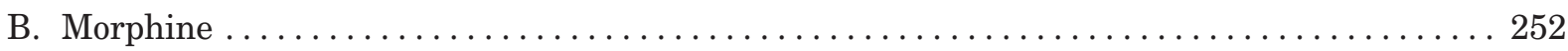

1. Morphine effects on brain-derived neurotrophic factor signaling $\ldots \ldots \ldots \ldots \ldots \ldots 252$

2. Effects of brain-derived neurotrophic factor infusion on opiate-induced cellular

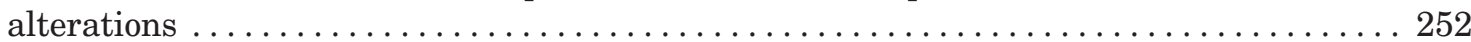

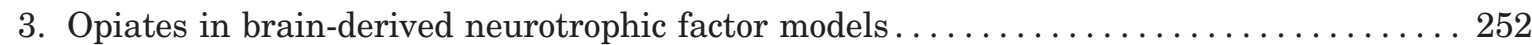

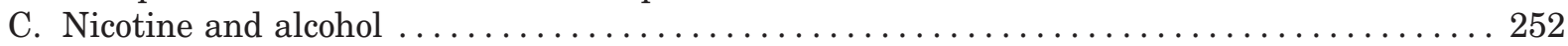

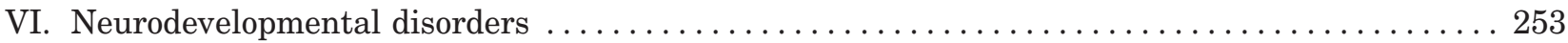

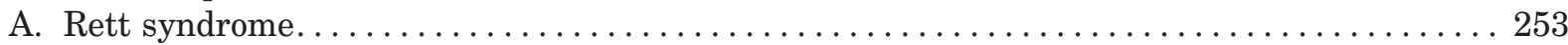

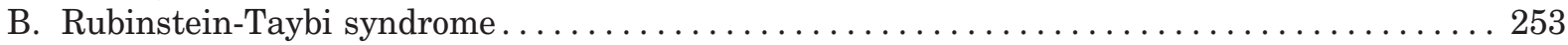

VII. Brain-derived neurotrophic factor and eating disorders $\ldots \ldots \ldots \ldots \ldots \ldots \ldots \ldots \ldots \ldots \ldots \ldots \ldots \ldots$

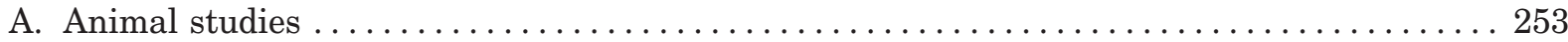

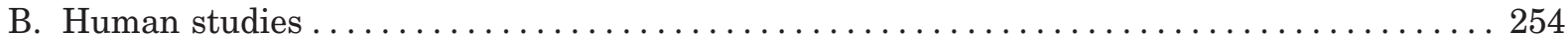

VIII. Brain-derived neurotrophic factor-based therapeutics . . . . . . . . . . . . . . . . . . 254

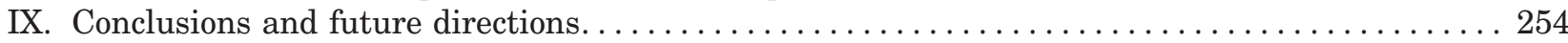

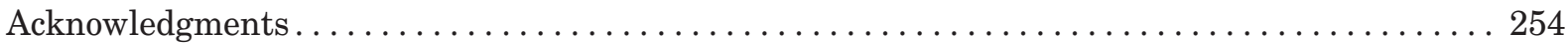

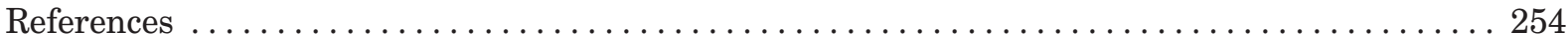

\begin{abstract}
Brain derived neurotrophic factor (BDNF) is the most prevalent growth factor in the central nervous system (CNS). It is essential for the development of the CNS and for neuronal plasticity. Because BDNF plays a crucial role in development and plasticity of the brain, it is widely implicated in psychiatric diseases. This review provides a summary of clinical and preclinical evidence for the involvement of this ubiquitous growth factor in major depressive disorder, schizophre-
\end{abstract}

nia, addiction, Rett syndrome, as well as other psychiatric and neurodevelopmental diseases. In addition, the review includes a discussion of the role of BDNF in the mechanism of action of pharmacological therapies currently used to treat these diseases, such antidepressants and antipsychotics. The review also covers a critique of experimental therapies such as BDNF mimetics and discusses the value of BDNF as a target for future drug development.

\section{Introduction}

Neurotrophins are an important class of signaling molecules in the brain responsible for axon targeting, neuron growth, maturation of synapses during development, and synaptic plasticity. This family of molecules includes nerve growth factor $\left(\mathrm{NGF}^{1}\right)$ (Levi-Montalcini, 1966), brainderived neurotrophic factor (BDNF) (Barde et al., 1982), as well as neurotrophins 3 and 4 (Hohn et al., 1990). Of these,

\footnotetext{
${ }^{1}$ Abbreviations: $5 \mathrm{HT}$, serotonin; AN, anorexia nervosa; AP, apomorphine; BDNF, brain-derived neurotrophic factor; BN, bulimia nervosa; CBP, CREB binding protein; CPP, conditioned place preference; CREB, cAMP response-element binding protein; DAT, dopamine transporter; LTP, long-term potentiation; MAM, methylazoxymethanol acetate; MAPK, mitogen-activated protein kinase; MeCP2, methylated CpG binding protein; NAc, nucleus accumbens; NGF, nerve growth factor; NH125, 1-benzyl-3-cetyl-2-methylimidazolium iodide; NMDA, $N$-methyl-D-aspartate; NVHL, neonatal ventral hippocampal lesions; PI3K, phosphatidylinositol 3-kinase; PLC, phospholipase C; PTSD, post-traumatic stress disorder; RTS, RubinsteinTaybi syndrome; RTT, Rett syndrome; SNP, single-nucleotide polymorphism; SSRI, selective serotonin-reuptake inhibitor; TH, tyrosine hydroxylase; TrkB, tropomyosin-related kinase B; VTA, ventral tegmental area.
}

BDNF is the best characterized in terms of its role in synaptic plasticity (Lohof et al., 1993; Levine et al., 1995, 1998; Kossel et al., 2001) and its potential role in the disease pathology or treatment of many psychiatric diseases (Duman and Monteggia 2006). In this review, we will provide background on the role of BDNF in the brain, how BDNF may be involved in psychiatric diseases, and finally how BDNF may serve as a therapeutic target for treatment of these disorders.

\section{A. Brain-Derived Neurotrophic Factor Signaling through Tropomyosin-Related Kinase B Receptors}

The gene structure of BDNF is quite complex and has recently been reviewed for rodent (Liu et al., 2006; Aid et al., 2007) and human (Liu et al., 2005). The rodent BDNF gene contains nine promoters, each of which precedes an exon (I-IX) that through alternative slicing can result in a large number of BDNF transcripts that all contain exon IX, which encodes the BDNF protein (Aid et al., 2007). Intriguingly, these transcription start sites are differentially activated by neuronal activity and DNA methylation 
status, resulting in the regulation of the transcripts. For example, neuronal depolarization enhances levels of exons I, IV, V, VII, VIII, and IX, whereas gene demethylation by DNA methyltransferase increases transcription of exons I, IV, V, VIII, and IX (Aid et al., 2007). Because exon IV seems to respond to activity and is a target for activity- and calcium-sensitive transcription factors, including cAMP response-element binding protein (CREB), upstreamstimulatory factors, calcium-responsive transcription factor, and methylated $\mathrm{CpG}$ binding protein (MeCP2), it is called the "activity-dependent" exon (Shieh et al., 1998; Tao et al., 1998; Tabuchi et al., 2002; Chen et al., 2003a,b; Martinowich et al., 2003). Although the differential regulation of these transcripts is important and may affect cellular localization, among other aspects, how this relates to neuropsychiatric disorders or treatment is unknown.

$\mathrm{BDNF}$ is synthesized as a precursor protein known as prepro-BDNF that is cleaved into pro-BDNF, which can then be further cleaved into mature BDNF (Lessmann et al., 2003). The significance of this precursor protein seems to be that the full-length proneurotrophins get folded (Heymach et al., 1996) and sorted (Lee et al., 2001) properly. Recent work has suggested that pro-BDNF $(35 \mathrm{kDa})$ is secreted in an activitydependent manner along with the enzyme tissue plasminogen activator, which cleaves pro-BDNF to mature BDNF (14 kDa) (Waterhouse and Xu, 2009). However, pro-BDNF is not an inactive precursor and has been shown to have effects in the central nervous system that are independent of mature BDNF.
Recent data suggest that pro-BDNF and mature BDNF activate different intracellular signaling pathways (Woo et al., 2005; Matsumoto et al., 2008; Yang et al., 2009). ProBDNF signals through the low-affinity neurotrophin receptor p75 that is believed to be involved in apoptosis (Roux and Barker, 2002; Lessmann et al., 2003). Mature BDNF signals through its high-affinity tropomyosinrelated kinase $\mathrm{B}$ (TrkB) receptor. When BDNF is bound to TrkB, it induces its dimerization and the receptor tyrosine kinase is autophosphorylated, leading to activation of intracellular signaling cascades, as well as augmentation of $\mathrm{N}$-methyl-D-aspartate (NDMA) receptor currents (Levine et al., 1998). There are at least three signaling transduction pathways that BDNF-TrkB activation can regulate (Fig. 1). The phospholipase C $\gamma$ (PLC $\gamma$ ) pathway, which leads to activation of protein kinase $\mathrm{C}$; the phosphatidylinositol 3-kinase (PI3K) pathway, which activates serine/ threonine kinase AKT; and the mitogen-activated protein kinase [MAPK, or extracellular signal related kinase (ERK)] pathway, which activates several downstream effectors. Each of these signaling pathways confer the unique function of BDNF on cells (for review, see (Mattson, 2008; Yoshii and Constantine-Paton, 2010). In brief, rapid synaptic and ion channel effects are thought to depend on PLC $\gamma$-mediated release of intracellular calcium stores, and longer-lasting effects involving transcription are considered to be downstream of PI3K and MAPK pathways; these effects will be discussed in greater detail in the following section. In addition, there is also evidence that BDNF may directly activate voltage-gated sodium chan-

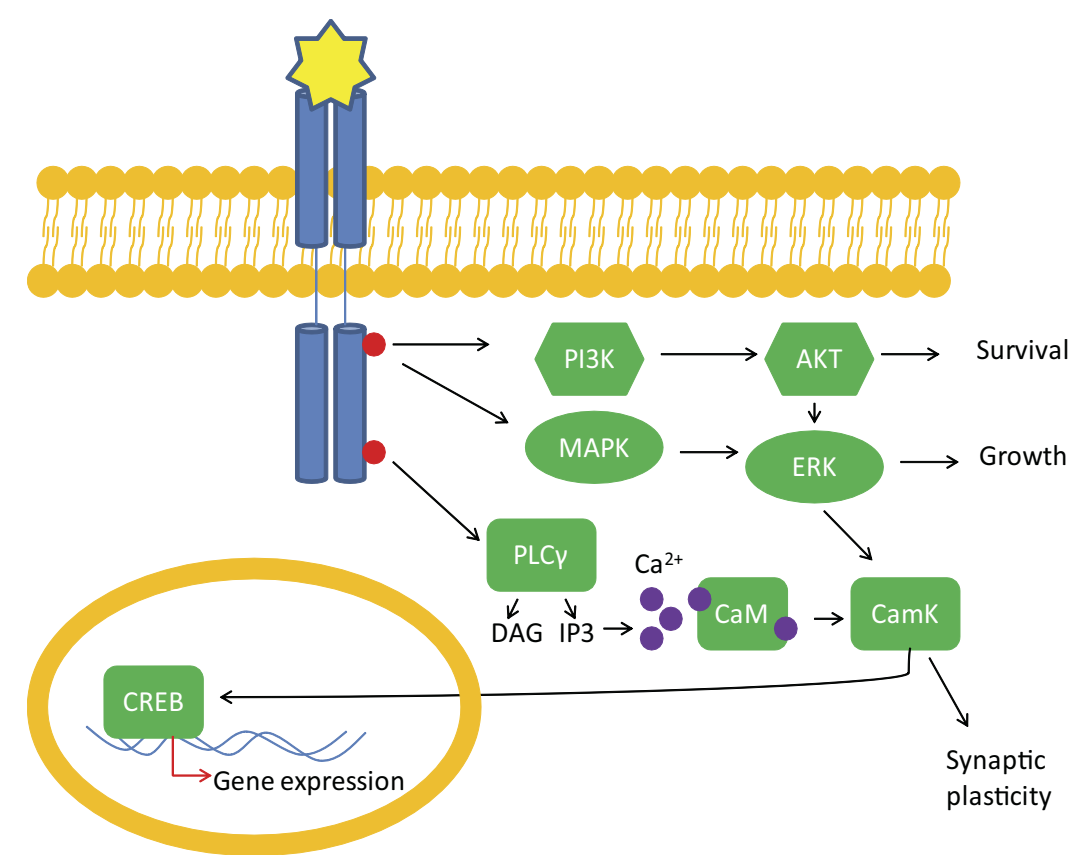

FIG. 1. Overview of BDNF signaling through TrkB receptors. Upon binding to BDNF, the receptor tyrosine kinase TrkB becomes phosphorylated. Phosphorylation at various sites leads to activation of downstream pathways. The PI3K pathway activates protein kinase B (AKT), leading to cell survival. The MAPK/ERK pathway leads to cell growth and differentiation. The PLC $\gamma$ pathway activates inositol trisphosphate (IP3) receptor to release intracellular calcium stores leading to enhanced calmodulin kinase (CamK) activity, leading to synaptic plasticity. All three pathways converge on transcription factor CREB, which can up-regulate gene expression. DAG, diacylglycerol. 
nels to mediate rapid depolarization of target neurons (Blum et al., 2002).

\section{B. Brain-Derived Neurotrophic Factor Functions in Neurons}

Throughout development, BDNF acts as a signal for proper axonal growth (Yoshii and Constantine-Paton, 2010). BDNF is secreted from target tissues, and TrkB receptors internalize upon ligand binding and signal to the nucleus of the cell to stimulate neurite outgrowth (Yoshii and Constantine-Paton, 2010). BDNF is known to be required for proper development and survival of dopaminergic, GABAergic, cholinergic, and serotonergic neurons (Pillai, 2008).

BDNF also serves essential functions in the mature brain in synaptic plasticity (Poo, 2001) and is crucial for learning and memory processes (Lu et al., 2008). BDNF and TrkB are localized at pre- and postsynaptic sites, where BDNF can be released in an activity-dependent manner (Waterhouse and $\mathrm{Xu}, 2009$ ). Presynaptic BDNF signaling promotes neurotransmitter release, whereas postsynaptic BDNF signaling is involved in enhancing various ion channel function including the $\alpha$-amino-3hydroxy-5-methyl-4-isoxazolepropionic acid receptor, the NMDA receptor, transient receptor potential cation channels, as well as sodium and potassium channels (for detailed review, see Rose et al., 2004). BDNF acts at both excitatory and inhibitory synapses (Kovalchuk et al., 2004), and experimental evidence suggests that BDNF may modulate both spontaneous and stimulated neuronal activity (Schuman, 1999; Tyler et al., 2006).

The action of BDNF signaling on synapses occurs within seconds of stimulation or application/release of the factor (Kovalchuk et al., 2004) and may support long-term potentiation (LTP) processes via sustained TrkB activation as a result of dendritic protein translation or transcription of BDNF (Kang and Schuman, 1996). This positive transcriptional feedback occurs through TrkB-mediated CREB activation, which binds to cAMP response element sites in the BDNF promoter to enhance gene transcription ( $\mathrm{Lu}$ et al., 2008). LTP is the lasting enhancement of synaptic strength between neurons that is initiated by synchronous depolarization, and this phenomenon is considered a cellular model for associational learning and memory processes. BDNF is known to facilitate LTP by converting early LTP to late LTP and by potentiating subthreshold activation to elicit LTP (Nagappan and Lu, 2005). Given this essential role of BDNF in LTP facilitation, it is not surprising that experimental loss of BDNF signaling through genetic models or pharmacological manipulation leads to impaired LTP (Patterson et al., 1996; Monteggia et al., 2004) and decreased learning and memory in behavioral paradigms (Lu et al., 2008).

Further studies of loss of BDNF signaling in the adult brain have led to the discovery of many more roles for $\mathrm{BDNF}$ in the modulation of behavior. In addition to its importance in learning (for review, see Cowansage et al., 2010), studies have revealed BDNF's involvement in cognition as well as mood-related behaviors. For this reason, $\mathrm{BDNF}$ is widely studied in relation to neuropsychiatric diseases including but not limited to major depressive disorder, schizophrenia, bipolar disorder, addiction, Rett syndrome, and eating disorders.

\section{Major Depressive Disorder and Therapies}

\section{A. Brain-Derived Neurotrophic Factor Regulation by Major Depressive Disorder and Treatments}

Major depressive disorder (MDD) is a leading cause of disability worldwide. The clinical presentation of MDD consists of a spectrum of neuropsychiatric symptoms, including anxiety, feelings of inappropriate guilt, loss of pleasure, appetite changes, and sleep disturbances (Shelton, 2007). It is noteworthy that the incidence of MDD is twice as high in women compared with men, although the reason for this difference is currently unknown (Becker et al., 2007). Pharmacological therapies for treatment of MDD include selective serotonin-reuptake inhibitors (SSRIs), tricyclic antidepressants, monoamine oxidase inhibitors, and norepinephrine reuptake inhibitors. These drugs target monoamine neurotransmitter systems to increase signaling at the synapse, which suggests an essential role for monoaminergic systems in mood-related behavior. However, given that these drugs have rapid synaptic effects but are associated with delayed onset of clinical efficacy, it has been proposed that molecular targets downstream of serotonergic or noradrenergic signaling are responsible for antidepressant efficacy.

Researchers are therefore interested in identifying direct targets for MDD therapy to treat patients more rapidly and effectively. MDD has a genetic component of approximately $50 \%$, which indicates that environmental effects are a significant contribution to disease onset (Shelton, 2007). Stressful events, including early life trauma as well as acute stressors, correlate strongly with the occurrence of MDD (Charney and Manji, 2004). Intriguingly, BDNF seems to be a molecular substrate of stress, because data have demonstrated that BDNF expression is reduced by stress, an important risk factor for MDD (Martinowich et al., 2007). Furthermore, antidepressant treatment has effects on BDNF levels opposite those of stress or depression (Castrén and Rantamäki, 2010). Given that BDNF expression is decreased by stress and MDD, increased by antidepressants, and normalized in patients with MDD taking an antidepressant, many investigators have focused on BDNF as a "biomarker" and also a potential target for treatment of MDD.

1. Brain-Derived Neurotrophic Factor Expression in Human Patients with Depression. Stress-related disorders, including MDD, correspond anatomically to a reduction in hippocampal volume in patients (Bremner et al., 2000). The hippocampus receives input from the hypothalamic-pituitary-adrenal axis that modulates 
stress responses and is important in emotional cognition and memory (McEwen, 2005). BDNF and TrkB levels are decreased in regions of the hippocampus in postmortem tissue taken from suicide victims or patients with MDD or in the serum of patients with MDD (Castrén et al., 2007; Castrén and Rantamäki, 2010; Thompson Ray et al., 2011). Given that BDNF expression is decreased by stress, structural changes in the hippocampus related to MDD may be attributed in part to the reductions in BDNF and TrkB (Yu and Chen, 2011). Another region of the brain essential to emotional processing, the prefrontal cortex, has been examined in relation to pathological features of MDD. In humans with MDD, this brain region is also decreased in volume, which is correlated with decreased BDNF and TrkB levels (Dwivedi et al., 2003; Castrén, 2004; Pandey et al., 2008). These findings suggest that both stress and MDD affect BDNF expression in limbic regions.

It is intriguing that BDNF expression is enhanced by MDD in other areas of the brain. Studies have revealed that BDNF protein is increased in the nucleus accumbens (NAc) tissue from human patients with MDD (Krishnan et al., 2007). Another interesting neuroanatomical correlate of MDD is hypertrophy of the amygdala (Tebartz van Elst et al., 2000; Frodl et al., 2002). Although it is unclear in human patients whether BDNF is involved in this structural abnormality, preclinical studies suggest that BDNF is enhanced in the amygdala in response to stress ( $\mathrm{Yu}$ and Chen, 2011). Taken together, these findings uncover an emergent MDD circuitry in which BDNF signaling is increased in the amygdala and nucleus accumbens and decreased in the hippocampus and prefrontal cortex.

2. Brain-Derived Neurotrophic Factor Expression in Patients Treated with Antidepressants. BDNF is positively regulated by antidepressant treatment in humans. Postmortem tissue studies demonstrate that BDNF levels are increased in the hippocampus and cortex after long-term antidepressant use. In addition, studies in live patients indicate that serum levels of $\mathrm{BDNF}$ are normalized in patients suffering from depression after long-term antidepressant treatment (Duman and Monteggia, 2006), a finding that has been validated after meta-analyses of multiple studies (Sen et al., 2008). However, studies of BDNF in postmortem tissue are correlative, and the exact origin and function of serum-derived BDNF remain unclear. Some of these assumptions have been tested in preclinical models of reduced BDNF signaling or in animal models of depression.

\section{B. Brain-Derived Neurotrophic Factor in Behavioral Models of Depression}

In rodents, chronic stress is a generally accepted model of depression because it leads to neurochemical and behavioral alterations that are analogous to those observed in depressed human patients, including increases in stress hormones, hippocampal atrophy, increased anxiety- and depression-related behaviors, and cognitive impairments (McEwen and Magarinos, 1997; Willner, 2005; Yan et al., 2010). Studies have repeatedly shown that chronic restraint stress or unpredictable stress can lead to decreases in hippocampal mRNA and protein levels of BDNF in mice and rats (Duman and Monteggia, 2006). On a related note, long-term administration of corticosterone, the rodent stress hormone, is sufficient to produce decreases in hippocampal BDNF expression, further implicating the role of stress in these molecular alterations (Jacobsen and Mørk, 2006).

\section{Brain-Derived Neurotrophic Factor Animal Models.}

a. Baseline behavior. To determine whether BDNF is required for normal depression-like behavior, multiple animal models of deficient BDNF signaling have been produced. Constitutive BDNF knockout mouse models have developmental brain abnormalities and die soon after birth (Ernfors et al., 1994). Therefore, investigators have turned to heterozygous, conditional, and region-specific knockout or knockdown models to study depression-related behavior in adult mice. BDNF heterozygous mice display $\sim 50 \%$ reduction of mRNA and protein throughout the animal. Studies using BDNF heterozygous mice show no compelling evidence of alterations in depression-like behavior (Chourbaji et al., 2004). However, baseline behaviors in BDNF heterozygous mice may be difficult to interpret because constitutive reduction of BDNF over the course of development may result in developmental compensation or it may be that $50 \%$ expression of BDNF is sufficient for normal behavioral phenotypes. Therefore, investigators have used conditional and inducible genetic models to remove BDNF in a regionally and temporally dependent manner. In mouse models in which BDNF is deleted from forebrain neurons later in development, there are not profound changes in depression-related behavior (Monteggia et al., 2004), although female mice lacking BDNF may display alterations in depression behavior in certain assays (Monteggia et al., 2007). A potential issue with this type of deletion is that behavioral effects cannot be attributed to specific neural circuits. However, all of these lines of mice consistently display an inability to respond to antidepressant treatment, revealing an essential role for BDNF in the manifestation of behavioral antidepressant responses (Monteggia et al., 2004; Malberg and Blendy, 2005; Tardito et al., 2006; Monteggia et al., 2007; $\mathrm{Hu}$ and Russek, 2008).

To more accurately target particular brain regions, researchers are using viral-mediated deletion techniques to remove BDNF from spatially restricted brain regions. These studies have added to our understanding of how BDNF operates in neural circuitry and have revealed conflicting evidence on the contribution of particular brain regions to depression-related behavior (Fig. 2, A and B). Adachi et al. (2008) demonstrated that localized deletion of BDNF in the cornu ammonis 1 or dentate gyrus subregions 

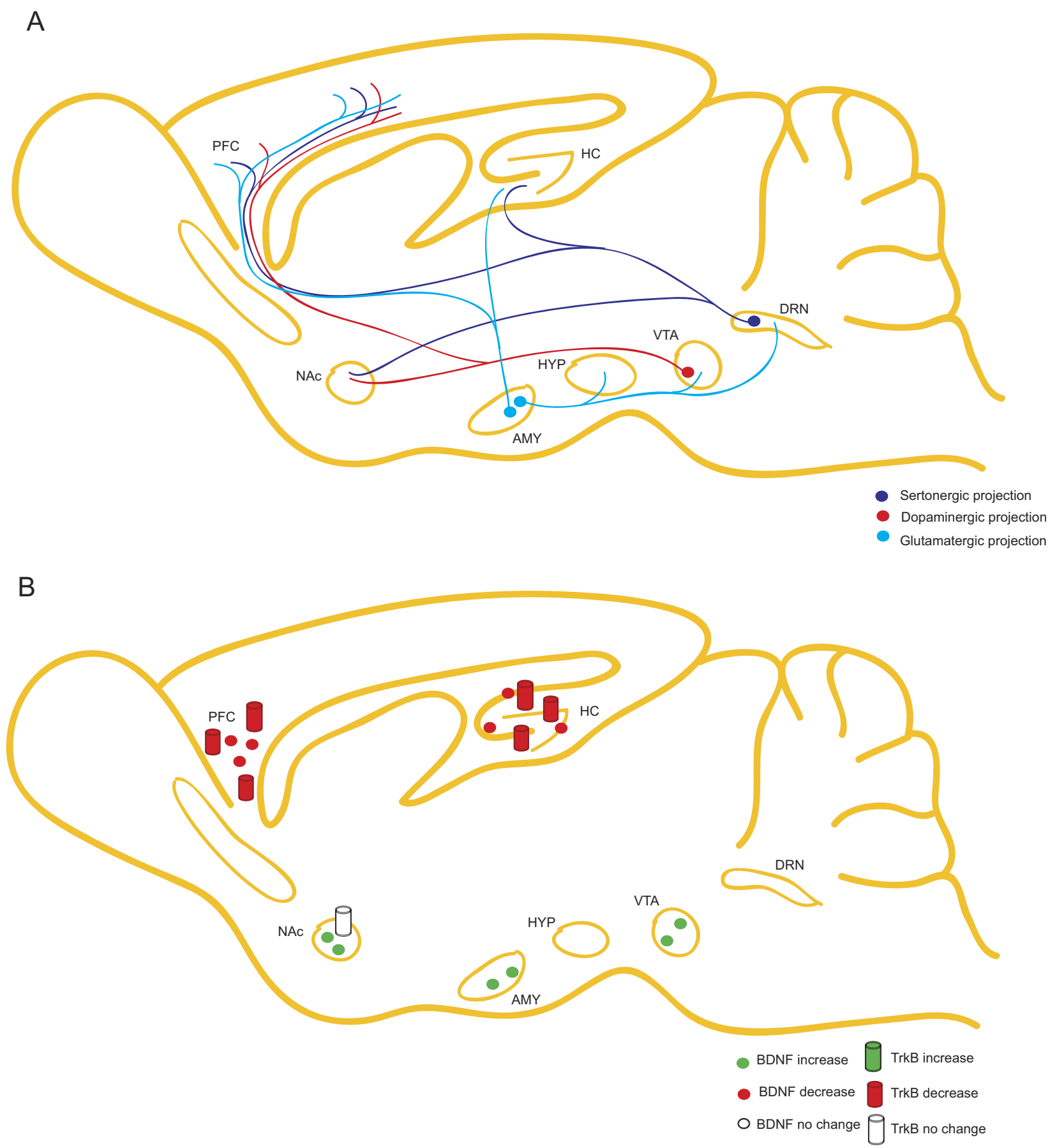

FIG. 2. Schematic of the role of BDNF in "depression" neurocircuitry. A, depiction of serotonergic, GABAergic, and glutamatergic projection neurons in regions of interest in MDD, including hippocampus (HC), dorsal raphe nucleus (DRN), cortex (PFC), amygdala (AMY), VTA, NAc, and hypothalamus (HYP). B, schematic of BDNF mRNA or protein regulation by depression either from studies of patients with MDD or from studies of animal models of stress. BDNF is down-regulated by MDD or stress in the hippocampus and cortex but increased by these stimuli in the nucleus accumbens and amygdala.

of hippocampus does not alter baseline depression behavior, although dentate gyrus expression of BDNF is required for antidepressant efficacy. However, regionspecific deletion of BDNF in the mesolimbic dopamine neurons in the ventral tegmental area (VTA) exerts an opposing effect, resulting in an antidepressant-like response (Berton et al., 2006; Krishnan et al., 2007). Theories in the field explain this discrepancy as an illustration of either the complex circuitry associated with mood-related behaviors (Castrén et al., 2007) or that deletion of BDNF and its precursor pro-BDNF results in distinct behavioral alterations in different brain areas (Martinowich et al., 2007); sufficient experimental evaluation of these proposals has not yet been undertaken. Further examination of the region-specific contribution of BDNF to depression-like behavior and antidepressantefficacy will be important to 
determine how brain circuitry influences these behavioral processes.

b. Stress paradigms. BDNF alone may not be sufficient to explain depression-related behaviors, but it remains an important risk factor for depression. Researchers have examined the role that BDNF plays in susceptibility to developing stress-related mood disorders, but preclinical investigations have not yet demonstrated how loss of BDNF alters vulnerability to stress (Advani et al., 2009; Autry et al., 2009). Differences in observations are likely to arise as a result of variations in the type of stressors, duration of stress, choice of behavioral assay or endpoint, mouse strain, and brain pathway examined. Some studies illustrate that BDNF heterozygous mice have altered depression-related behavior after acute or subchronic stress (Advani et al., 2009). Research on conditional or inducible BDNF mutants suggests that depression behavior in male mice from these lines is indistinguishable from that in control mice after chronic mild stress (Ibarguen-Vargas et al., 2009), although in female mutant mice, alterations in depression behavior may be more pronounced (Autry et al., 2009). After chronic social stress, BDNF deletion in the VTA reduces depression-related behavior (Berton et al., 2006), again suggesting differences in circuitry or $\mathrm{BDNF} /$ pro-BDNF functions. Further investigation is required, but current research indicates that BDNF potentially affects stress-induced behavior in a limited and gender-specific manner.

2. Brain-Derived Neurotrophic Factor Produces an Antidepressant Response in Animal Models. Evidence suggests that, although its role in depression symptoms is complex, BDNF is essential for antidepressant efficacy. Similar to findings in human tissue, BDNF mRNA and protein expression are increased after long-term antidepressant therapies, such as electroconvulsive therapy, and many drugs, including SSRIs, norepinephrine reuptake inhibitors, tricyclic antidepressants, and atypical compounds in corticolimbic brain areas, including the hippocampus in animal models (Nibuya et al., 1995; Altar et al., 2003; Balu et al., 2008). Moreover, infusion of BDNF into the midbrain, ventricles, or regions of the hippocampus results in increased antidepressant-like behavior (Shirayama et al., 2002; Hoshaw et al., 2005; Hu and Russek, 2008). Although many growth factors such as NGF and insulin growth factor are also known to increase after antidepressant treatment and to cause behavioral effects similar to those observed after BDNF infusion (for review, see Duman and Monteggia, 2006), a preponderance of data suggests that animal models lacking BDNF are unable to respond to antidepressants (Saarelainen et al., 2003; Monteggia et al., 2004, 2007; Adachi et al., 2008). In support of these findings, overexpression of a dominant-negative TrkB (TrkB.T1) leads to loss of antidepressant efficacy, which suggests that TrkB activation is required for antidepressants to produce behavioral effects (Saarelainen et al., 2003). In a subsequent study, antidepressant drugs were found to rapidly activate the TrkB receptor and PLC $\gamma$ signaling, which suggests that this intracellular pathway is a common mechanism for antidepressant drug action (Rantamäki et al., 2007). Taken together, these data indicate that BDNF via TrkB activation and downstream signaling is both necessary and sufficient for antidepressant behavioral responses.

3. Interplay between Brain-Derived Neurotrophic Factor and the Serotonergic System. BDNF has been shown to affect the function of serotonergic neurons. BDNF and the TrkB receptor are expressed on serotonergic neurons in the raphe nucleus, where they can mediate effects on these neurons (Merlio et al., 1992). Previous work has also demonstrated that BDNF from the hippocampus can be retrogradely transported to the raphe nucleus neurons (Anderson et al., 1995), suggesting a complex interplay in how this neurotrophin can affect serotonergic function. In the context of MDD, the findings that BDNF is necessary for antidepressant responses)such as those from SSRIs in animal models) and that SSRIs regulate BDNF expression further highlight the link between these two systems. Studies have attempted to identify structural alterations in mouse models of BDNF deficiency related to the serotonergic system. Mice heterozygous for BDNF show changes in later life in serotonergic innervation of target regions such as the cortex, the hypothalamus, and the hippocampus that could be linked to depression (Lyons et al., 1999). These changes occur in a regions specific manner; serotonergic innervation is depleted in the cortex and the hypothalamus, whereas it is enhanced in the hippocampus (Lyons et al., 1999).

The idea that SSRIs increase extracellular 5HT levels, which then promotes up-regulation of BDNF expression, suggests important roles for 5HT receptors in SSRI efficacy (for review, see Gardier, 2009). Conversely, stress can down-regulate components of the $5 \mathrm{HT}$ system, including specific receptor subtype expression and/or function, which may then alter BDNF expression (for review, see Gingrich and Hen, 2001). A recent study demonstrated this dissociation between the impact of $\mathrm{BDNF}$ on $5 \mathrm{HT}$ receptor number and function (Hensler et al., 2007). In this study, inducible forebrain BDNF knockout mouse show unaltered 5 HT1a serotonin receptor number in the hippocampus although the regulation of these $5 \mathrm{HT} 1 \mathrm{a}$ receptors in the presence of the stress hormone corticosterone is affected by loss of BDNF (Hensler et al., 2007). This review will not focus further on the link between the 5HT receptor subtypes and $\mathrm{BDNF}$, given the large number of $5 \mathrm{HT}$ receptor subtypes and their putative roles in depression and antidepressant responses.

Studies have inquired into the relationship between $\mathrm{BDNF}$ and the serotonin transporters, which clear 5HT from the synapse and are the molecular target of SSRIs. In vitro studies show that BDNF dose-dependently decreases $5 \mathrm{HT}$ uptake, suggesting that BDNF affects the function of 
serotonin transporters (Mössner et al., 2000). In addition, detailed studies of extracellular serotonin levels using high-speed chronoamperometry reveal an in vivo deficiency in synaptic serotonin removal in mice heterozygous for BDNF (Daws et al., 2007). In this study, the authors reported that BDNF heterozygotes are less responsive to the effects of SSRI drugs, which typically increase extracellular serotonin in wild-type mice (Daws et al., 2007). In agreement with these findings, in vivo microdialysis studies demonstrate that BDNF heterozygous mice display enhanced extracellular serotonin (Deltheil et al., 2008b). BDNF heterozygotes were also found to have decreased serotonin outflow after treatment with various SSRIs, again suggesting that BDNF is involved in the action of SSRIs (Deltheil et al., 2008b). Investigators further showed that this impact of BDNF on 5HT function is region-specific, indicating that BDNF heterozygous mice display blunted $5 \mathrm{HT}$ outflow in ventral hippocampus after treatment with SSRIs (Deltheil et al., 2008a). These data suggest that BDNF may serve to provide functional modulation of the serotonergic system at the level of both the receptor and the transporter. Future studies are necessary to further delineate this link between BDNF and serotonergic system functionality.

\section{Association of Brain-Derived Neurotrophic Factor and Neurogenesis in Depression and \\ Antidepressant Treatment?}

Because of the delay in clinical efficacy of antidepressants, investigators have searched for downstream cellular processes that may confer therapeutic effects. One process of interest in addition to BDNF-mediated synaptic plasticity enhancement is augmented hippocampal neurogenesis, which occurs on approximately the same time-scale as therapeutic effects of antidepressants (3-4 weeks). Studies have demonstrated that increased cell proliferation in the hippocampus is associated with MDD treatments such as electroconvulsive therapy and pharmacological therapies (for review, see Malberg and Blendy, 2005). Ablation of neuronal proliferation by cranial irradiation resulted in attenuation of antidepressant responses, suggesting that antidepressants were mediating their therapeutic effect through neurogenesis (Santarelli et al., 2003). However, Holick et al. (2008) suggested that the link between neurogenesis and antidepressant responses may be dependent on mouse strain. Intriguingly, BDNF heterozygous mice have normal neurogenesis but are unable to respond to antidepressants, suggesting that the BDNF-dependent effect on antidepressant efficacy is independent of neurogenesis (Duman et al., 2001). Furthermore, clinical studies have demonstrated that ketamine (Berman et al., 2000; Zarate et al., 2006) and scopolamine (Furey and Drevets, 2006; Drevets and Furey, 2010) may have antidepressant effects within hours or days, calling into question the contribution of neurogenesis in the mechanism of rapid alteration in mood states. Taken together, these observations suggest that neurogenesis may not be an essential mech- anism by which antidepressants exert behavioral effects and that the link to BDNF, a bona fide target of antidepressants, is unclear.

\section{Brain-Derived Neurotrophic Factor Polymorphisms}

Researchers have examined the BDNF gene for singlenucleotide polymorphisms (SNPs) that may be linked to MDD. The most common BDNF SNP in humans is at codon 66, resulting in the Val to Met (V66M) protein variant, which prevents the activity-dependent release of BDNF (Egan et al., 2003). Although this polymorphism does seem to affect human cognition, the contribution of this mutation to the pathological features of MDD or to suicidality remains unclear (Dwivedi, 2010). Recent studies have revealed that men homozygous for the mutation may be at greater risk for MDD (Frielingsdorf et al., 2010). Other studies suggest that this mutation may increase susceptibility for MDD after early-life stress (Gatt et al., 2009). Although mouse models of the V66M mutation seem to have neuronal development defects that lead to reduced hippocampal volume, this structure reduction does not seem to contribute to depression-like behavior in rodents (Frielingsdorf et al., 2010). Whether this allele is associated with susceptibility to stress-induced depressionrelated behavior has not been thoroughly examined in mouse models (Martinowich et al., 2007). At present, it is not yet clear whether BDNF polymorphisms contribute to expression of MDD symptoms or antidepressant efficacy, so further work will be necessary to examine this possibility.

\section{Brain-Derived Neurotrophic Factor and Other Mood-Related Disorders}

\section{A. Bipolar Disorder}

Bipolar disorder (BD) affects approximately $1 \%$ of the population and consists of alternations between depressive and manic episodes (Shaltiel et al., 2007). Like MDD, stressful life events seem to trigger manic episodes in patients with BD (Sanacora, 2008). Treatment for BD often includes mood stabilizers such as lithium or valproic acid and may also include antidepressant.

Both lithium and valproic acid increase BDNF expression in corticolimbic brain regions and engage signaling pathways downstream of the TrkB receptor much like antidepressant therapies (Hashimoto et al., 2002; Chen and Manji, 2006; Sanacora, 2008). In addition, BDNF protein levels are decreased in post mortem hippocampal tissue (Knable et al., 2004), and serum BDNF levels are decreased in patients with BD (Sanacora, 2008). The V66M BDNF allele is strongly correlated to BD (NevesPereira et al., 2002; Sklar et al., 2002; Lohoff et al., 2005). Taken together, these data implicate misregulation of trophic signaling pathways in the disease state as well as in therapeutic efficacy. Study of BDNF animal models with respect to $\mathrm{BD}$-associated behavioral paradigms may reveal 
a new appreciation for the role of BDNF in this debilitating mood disorder.

\section{B. Anxiety-Related Disorders}

Anxiety disorders in humans are pathological responses to stressful situations. Anxiety-related disorders include generalized anxiety disorder as well as phobias, panic disorder, obsessive-compulsive disorders, and post-traumatic stress disorder (PTSD) (Hovatta and Barlow, 2008). These disorders affect approximately one in five Americans annually (Kessler et al., 2005). Approximately $30 \%$ of the risk for anxiety-related disorders can be attributed to heritable traits (for review, see Hovatta and Barlow, 2008). Because of the stress-induced nature and the high comorbidity with $\mathrm{MDD}, B D N F$ is a gene of interest in the study of anxietyrelated disorders.

1. Anxiety in Brain-Derived Neurotrophic Factor Mouse Models. Conditional mutants for BDNF using lines in which the gene was deleted in broad forebrain areas reveal decreased anxiety in female mice (Monteggia et al., 2007). However, in a study using a different mouse line, an inducible BDNF mutant, female mice showed greater susceptibility after stress for enhanced anxiety than stressed male mutant mice (Autry et al., 2009). Mice homozygous for the V66M allele show increased anxiety-related behavior (Chen et al., 2006). Collectively, these data suggest that alterations in BDNF expression may affect anxiety-related behavior, although the neural circuitry involved in these processes remains to be determined.

2. Brain-Derived Neurotrophic Factor and Anxiety in Human Studies. Human studies of anxiety-related disorders associated with the V66M allele uncover mixed results. In some studies, association of the V66M SNP with enhanced anxiety is revealed (Montag et al., 2010), whereas meta-analysis has no significant impact on anxiety to this mutation (Frustaci et al., 2008). Similar to data in patients with MDD, there may be an interaction of early-life stress and BDNF SNPs, which precipitate anxiety-related disorders (Gatt et al., 2009). A recent study has demonstrated impairments in fear extinction response in human V66M carriers (Soliman et al., 2010). Taken together with the potential for anxiety propensity in these humans, this allele may be relevant in patients with PTSD (Soliman et al., 2010).

3. Potential Link between Brain-Derived Neurotrophic Factor and Post-Traumatic Stress Disorder. Investigators are studying the role of BDNF in abnormal fear memory and extinction (Frielingsdorf et al., 2010). Pathological fear is a central feature of PTSD, so taken together with the responsiveness to stress and involvement in memory, BDNF is a gene of interest for PTSD. In rodent studies, the V66M mutation is correlated with impaired fear memory (Chen et al., 2006), similar to findings with another BDNF mouse model (Monteggia et al., 2004). Targeted knockdown or inhibition of BDNFTrkB signaling in the amygdala results in loss of fear memory acquisition (Rattiner et al., 2004). Hippocampal deletion of BDNF leads to disrupted extinction of fear memory (Heldt et al., 2007). Systemic administration of a TrkB agonist, 7,8-dihydroxyflavone seems to enhance extinction of fear learning, implicating its potential usefulness in PTSD therapy (Andero et al., 2011). Taken together, these data suggest that BDNF is essential for fear memory formation and extinction in multiple corticolimbic structures and may be a therapeutic target for PTSD.

\section{Schizophrenia}

Schizophrenia (SZ) is a complex, heterogeneous disease characterized by psychosis that affects approximately $1 \%$ of the population (Regier et al., 1993). Core negative symptoms of SZ include cognitive deficits, social avoidance, and flat affect; positive symptoms include paranoia, hyperactivity, and psychosis. Linkage analyses reflect a high impact of genetics on incidence of SZ, although environmental effects such as life events and prenatal and early development may contribute to the disease (Lang et al., 2007a). Pharmacotherapies for SZ mainly target psychosis and are grouped into typical and atypical (first and second generation, respectively) antipsychotic classes that primarily inhibit the dopaminergic system. Although the mechanisms of these drug classes are not fully understood, it is generally accepted that typical antipsychotics such as haloperidol, raclopride, and chlorpromazine have high affinity at dopamine receptors, which confers more side effects such as tremors (Seeman, 2002). Atypical antipsychotics such as clozapine and olanzapine may dissociate from the dopamine faster and in turn confer fewer side effects (Seeman, 2002). Given the complex pathology of schizophrenia, several neurotransmitter systems and molecular signals have been implicated in SZ. Studies have demonstrated that patients with SZ have alterations in brain morphology (Mueser and McGurk, 2004) and altered activity levels in various cortical and limbic brain regions compared with healthy controls (Goghari et al., 2010). Furthermore, many neurotransmitter systems including dopamine (Heinz and Schlagenhauf, 2010), the target for antipsychotic treatments; GABA (Volk et al., 2000), the primary inhibitory transmitter; and glutamate (Javitt, 2010), the major excitatory neurotransmitter, have been implicated in structural and neurochemical changes associated with SZ.

\section{A. Brain-Derived Neurotrophic Factor and Schizophrenia}

Because BDNF is involved in development, neurotransmission, and is also reactive to environmental stimuli, it has been studied in the pathophysiology of SZ. It has been proposed that developmental abnormalities, as well as persistent cognitive and emotional dysfunction that occur in development, including circuit-level, genetic, or environmental alterations in BDNF expression, lead to patholog- 
ical behavioral and neuronal features associated with SZ (Durany and Thome, 2004). Post mortem studies of SZ brain tissue have demonstrated alterations in BDNF in certain brain regions. Recent studies have shown that BDNF expression is increased in the frontal cortices of patients with SZ compared with controls (Takahashi et al., 2000), whereas others report that BDNF and TrkB are decreased in the cortices of patients with schizophrenia (Weickert et al., 2003; Hashimoto et al., 2005b). Some studies demonstrate enhanced BDNF protein levels in the hippocampus (Iritani et al., 2003), but others report decreased BDNF (Durany et al., 2001). Studies further show that the TrkB receptor is decreased in the hippocampus (Takahashi et al., 2000). It is possible that the various effects are due to antipsychotic therapy, because most patients with SZ included in these human studies have received long-term treatment for psychoses. Alternatively, these findings may suggest that SZ is associated with imbalanced circuit-level expression of BDNF, indicating either an altered developmental trajectory for BDNF expression, a secondary manifestation of pathological conditions, or antipsychotic action. Further study will be necessary to ascertain how age-related expression of BDNF may be changed in patients with SZ and how disease onset versus long-term antipsychotic therapy may affect BDNF levels.

Studies in live patients have assessed structural abnormalities as well as serum levels of BDNF associated with SZ. Magnetic resonance imaging studies have consistently shown that structural alterations in the brain are common in patients with SZ, including enlarged ventricles and reduced gray matter (Boos et al., 2007), particularly in the cortex and hippocampus (Steen et al., 2006). These findings suggest that possible misregulation of BDNF during brain development in SZ may contribute to reduced gray matter.

Studies have produced conflicting data regarding the levels of BDNF in serum of patients with SZ. Some detect decreased serum BDNF levels (Pillai, 2008); others report no such differences in control subjects versus patients with SZ (Durany and Thome, 2004). When investigators specifically examined patients with SZ who were taking antipsychotic drugs, certain drugs, such as clozapine, seem to increase serum BDNF levels, whereas others, such as risperidone, have no effect on BDNF (Pillai, 2008). It remains unclear how serum levels of BDNF correlate to brain levels and function.

\section{B. Antipsychotic Drug Effects on Brain-Derived Neurotrophic Factor Expression}

To further assess the validity of human serum data of patients with SZ who are taking antipsychotic agents, preclinical research has examined the effects on BDNF expression of treatment with such agents. Here again, results indicate that different antipsychotic drugs have diverse effects on BDNF expression in a brain-regionspecific manner. Haloperidol and risperidone seem to de- crease BDNF, whereas clozapine and olanzapine may increase BDNF levels in the hippocampus (Pillai, 2008), although other studies indicate that clozapine may have opposite effects in the hippocampus (Durany and Thome, 2004). These data do not definitively show how APs affect brain levels of BDNF.

\section{Altered Brain-Derived Neurotrophic Factor Levels in Animal Models of Schizophrenia}

Investigators have developed animal models of schizophrenia based on pathological features associated with the disease. Common models include neonatal ventral hippocampal lesions, which lead to structural abnormalities associated with SZ; gestational methylazoxymethanol acetate (MAM) exposure, mimicking defects in brain development thought to be correlated to SZ; and long-term amphetamine treatment, which may model psychosis symptoms observed in patients with SZ. In this section, we will discuss how these models affect levels of BDNF (Fig. 3, $\mathrm{A}$ and $\mathrm{B})$.

1. Neonatal Ventral Hippocampal Lesions. Neonatal ventral hippocampal lesions (NVHL) are made with ibotenic acid around postnatal day 7 to mimic the ventricular enlargement and developmental aspects associated with SZ (for review, see Tseng et al., 2009). Rodents with these lesions display behavioral symptoms analogous to SZ, including cognitive, social, and sensorimotor gating deficits, hyperactivity with sensitivity to psychotic druginduced effects, and abnormal stress responses (Tordjman et al., 2007). In terms of brain function, the NHVL model disrupts cortical networks and alters glutamatergic and GABAergic responses in adults (Pillai, 2008; Tseng et al., 2009). BDNF mRNA is reduced in the cortex and hippocampus in this model, mirroring some serum and post mortem brain studies (Pillai, 2008). Many studies suggest that the NVHL model for SZ has predictive validity for efficacy of risperidone and clozapine (Rueter et al., 2004; Richtand et al., 2006). How these lesions are linked to decreased BDNF levels, however, is unclear. Further study will be necessary to determine whether BDNF levels are decreased as a primary effect of lesion or secondary to systemic damage induced by the lesions.

2. Gestational Methylazoxymethanol Acetate Exposure. MAM is an antimitotic agent that causes a severe loss of neurons in the cortex and hippocampus when applied during embryogenesis (Di Luca et al., 1994). For modeling of SZ behavioral deficits such as hyperactivity and impaired cognition, the toxin is applied between days 11 and 17 in utero (Fiore et al., 2002; Lodge and Grace, 2008). Studies report decreased mRNA and protein levels of BDNF in the adult hippocampus after gestational MAM exposure (Pillai, 2008). These changes extend to other trophic factors, such as NGF, suggesting that there may be overall impairment of growth factor expression and, by extension, neuronal function after toxin application (Fiore et al., 2002). Antipsychotic effi- 

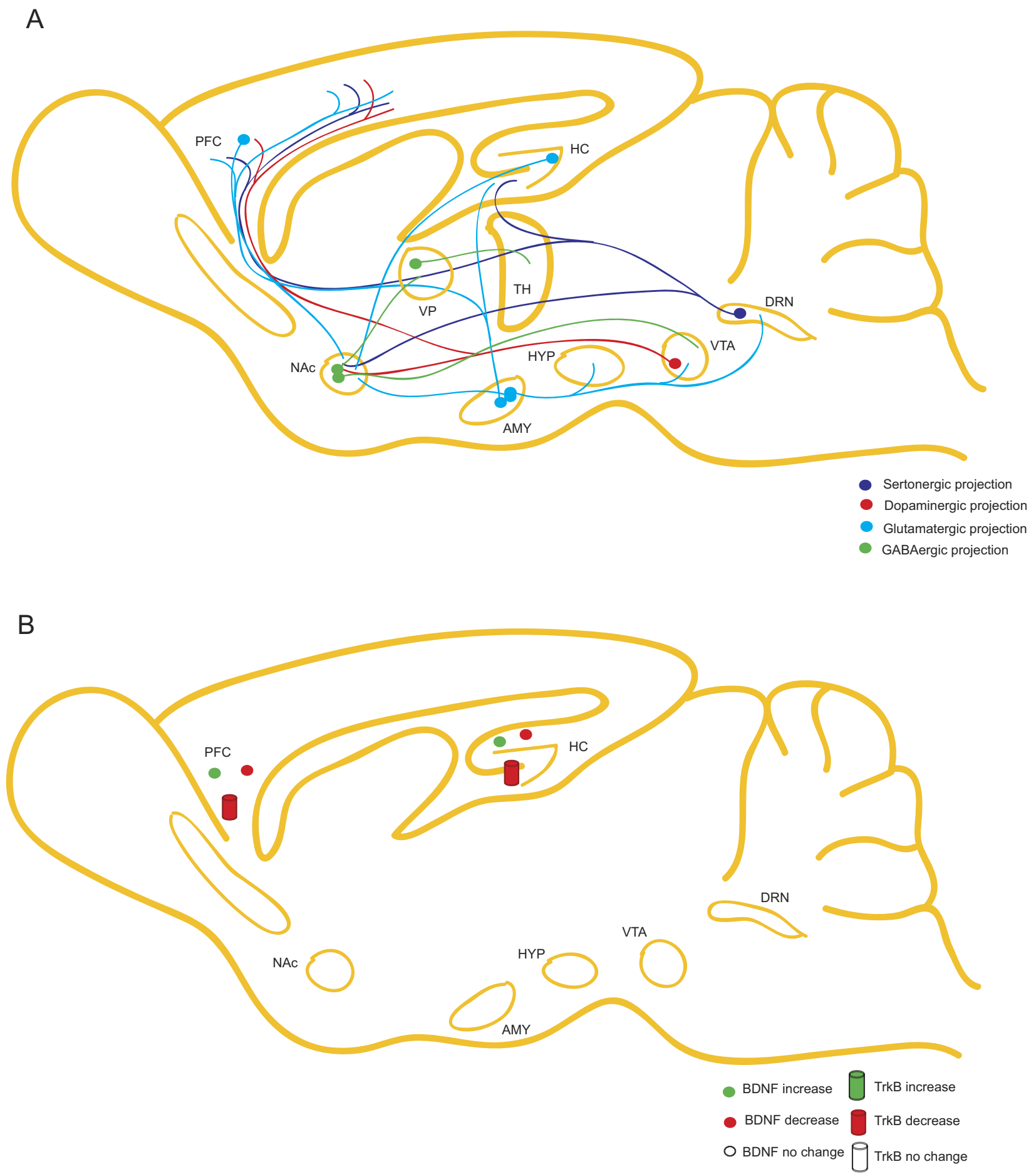

FIG. 3. Schematic of the role of BDNF in neurocircuitry associated with schizophrenia. A, nearly all neurotransmitter systems, including GABA, serotonin, glutamate, and dopamine, have been implicated in the pathophysiology of schizophrenia. HC, hippocampus; DRN, dorsal raphe nucleus: PFC, cortex; AMY, amygdala; HYP, hypothalamus; VP, ventral palladium; TH, tyrosine hydroxylase. B, studies have produced conflicting evidence on the regulation of BDNF and TrkB in patients with schizophrenia; some reports indicate that BDNF signaling is decreased in the cortex and hippocampus, whereas other reports show opposite results.

cacy has not yet been assessed in the gestational MAM exposure animal model. Again, with this model of SZ, it is difficult to know whether BDNF changes underlie behavioral symptoms associated with SZ. In this model as well as the NVHL model, it would be interesting to examine whether application of BDNF can rescue behavioral deficits associated with SZ.
3. Long-Term Amphetamine Administration. Investigators have focused on the role of dopamine in positive SZ symptoms such as psychosis, hallucinations, and paranoia because antipsychotic therapies target the dopaminergic system (Tamminga and Holcomb, 2005). Long-term amphetamine administration is used as a pharmacological model for psychotic symptoms of SZ 
(Ellison, 1994; Pillai, 2008) and has predictive validity for antipsychotics that typically inhibit dopaminergic receptors (Tordjman et al., 2007). Mice or rats given doses of amphetamine for a minimum of 7 days show psychosis-related behaviors reminiscent of SZ (Featherstone et al., 2007). Long-term amphetamine administration decreases BDNF protein levels in the hypothalamus and cortical regions (Angelucci et al., 2007a). This treatment also affects NGF in cortical areas, the hypothalamus, and the hippocampus (Angelucci et al., 2007a). These data suggest that long-term amphetamine exposure has a nonspecific effect on growth factors. Nevertheless, all of these animal models report BDNF decreases in corticolimbic brain regions although specificity of these changes is uncertain. Given that these models each replicate behavioral aspects of SZ and that serum and post mortem brain studies have reported decreased BDNF levels, these data all seem to suggest that BDNF may be important in the pathological features of SZ. Nonetheless, as stated previously, it remains to be tested whether the nature of BDNF changes and their relationship to SZ are causative or incidental.

\section{Brain-Derived Neurotrophic Factor Animal Models in Schizophrenia-Like Behaviors}

Because many animal models of SZ suggest alterations in BDNF, it is important to understand the impact of loss of BDNF on SZ-related behavioral measures. Preclinical paradigms that model SZ symptoms include associative and spatial memory tasks, sensorimotor gating tasks with or without AP treatment, novel environment locomotor activity and subsequent drug-induced sensitization, APinduced catalepsy, and social interaction. We have already discussed stress reactivity of various strains of BDNF models in the section covering MDD, so here we will focus on other aspects of SZ-related behavior.

\section{Brain-Derived Neurotrophic Factor Heterozygous} Mice. BDNF heterozygous mice have been assessed in a number of behavioral paradigms; the following is an overview of behaviors relevant to SZ. As previously mentioned, BDNF heterozygous mice display impairments in contextual fear conditioning that are in part rescued by hippocampal infusion of recombinant BDNF (Liu et al., 2004). In addition, this line of mice shows heightened locomotor activity (Kernie et al., 2000) as well as potentiated locomotor responses to amphetamine treatment (Dluzen et al., 2001; Saylor and McGinty, 2008), potentially implicating a lower threshold for psychosis-like behavior. Studies further indicate that BDNF heterozygous mice have deficits in sensorimotor gating (Dluzen et al., 2001).

2. Conditional/Inducible Brain-Derived Neurotrophic Factor Deletion Mice. Likewise, mice with postnatal neuronal deletion of BDNF have been assessed in multiple measures of SZ-related behavior. As in heterozygous mice, conditional and inducible lines of BDNF knockout mice exhibit compromised learning and mem- ory in spatial learning (Gorski et al., 2003; Monteggia et al., 2004, 2007) as well as contextual conditioning tasks. In addition, these mouse lines display increased locomotion in a novel environment (Monteggia et al., 2004, 2007). Knockout of BDNF expression during embryogenesis or adulthood in forebrain neurons does not seem to recapitulate morphological deficits associated with SZ (Hill et al., 2005); however, loss of BDNF in forebrain neurons does seem to be essential during both development and adulthood for maintaining normal function of GABAergic interneurons in the cortex (Glorioso et al., 2006).

Taken together, these rodent studies strongly suggest that BDNF may underlie aspects of positive symptoms such as psychosis and hyperactivity as well as cognitive deficits associated with SZ. Studies exploring the effect of BDNF deletion in social paradigms would reveal the involvement of BDNF in negative symptoms of SZ. Intriguingly, altered startle response in maternally separated rodents results in disrupted sensorimotor gating that is correlated to decreased BDNF levels in the hippocampus and striatum (Lippmann et al., 2007), suggesting that interaction of BDNF and stress in relation to SZ symptoms may be important to further investigate. Future study of the effect of APs in models of sensorimotor gating will be necessary to determine whether BDNF is essential for AP efficacy.

\section{E. Brain-Derived Neurotrophic Factor Polymorphisms and Schizophrenia}

Clinical studies have searched for genes associated with SZ to uncover potential contribution to the disease state. Polymorphisms in several genes have been identified including catechol-O-methyltransferase, disrupted in schizophrenia-1, and glutamic acid decarboxylase as well as BDNF (van Haren et al., 2008). Given the strong correlation between BDNF alterations and SZ in humans and in rodent models, researchers have examined polymorphisms in the gene. For the purposes of this review, we discuss two of the most well studied polymorphisms in SZ, V66M and C270T.

1. V66M Polymorphism. As mentioned in the section about MDD, the V66M polymorphism is known to reduce activity-regulated secretion of BDNF and is correlated with cognitive deficits in humans. Because impaired learning and memory are core symptoms of SZ, BDNF may be involved in this pathological condition. In addition, the V66M allele in some instances has been linked to development of SZ (Numata et al., 2006); although there is conflicting evidence (Naoe et al., 2007; Pillai, 2008). It will be necessary to determine whether these opposite outcomes are due to varying endophenotypes of the heterogeneous disease, patient population background, or affective symptoms versus developmental/neurochemical phenotypes of SZ.

2. C270T Polymorphism. The C270T polymorphism lies in the $5^{\prime}$ noncoding region of the $B D N F$ gene. The 
link between the C270T and SZ is currently not clear. Early studies showed that the frequency of this allele seems to be increased in the population of patients with SZ compared with healthy control subjects (Nanko et al., 2003; Szekeres et al., 2003). However, many other studies reported no association between SZ and this BDNF allele in various populations (Szczepankiewicz et al., 2005; Watanabe et al., 2006). The possibility that the samples were not large enough to detect an appreciable contribution of this low-frequency polymorphism has led scientists to combine data from these studies in a metaanalysis. However, the few studies that have combined data still do not offer a conclusive view of the contribution of this polymorphism to SZ (Jönsson et al., 2006; Watanabe et al., 2007; Xu et al., 2007). The conflicting results suggest that further examination of the association of the C270T polymorphism to SZ is necessary, particularly with respect to severity, symptom spectrum, and therapeutic treatments (Durany and Thome, 2004). Preclinical studies that are able to distinguish among susceptibility, disease mechanisms, and secondary changes induced by pathological features of SZ or by treatment can clarify this issue.

\section{Addiction}

Addiction is a psychiatric disorder caused by long-term use of drugs, resulting in substance abuse and/or dependence characterized by tolerance or sensitization to drug effects (Büttner, 2011). Withdrawal and craving in the absence of drug leads to enhanced susceptibility to relapse. According to the Office of National Drug Control Policy, addiction to illicit substances, tobacco, and alcohol results in a $\$ 600$ billion burden to the United States.

\section{A. Psychomotor Stimulants}

Amphetamine and cocaine use in the United States constitutes a large segment of illicit drug use. These drugs act through mechanisms that ultimately result in increased synaptic dopamine by action at the dopamine transporter (DAT). Cocaine inhibits the DAT, leading to increased synaptic levels of dopamine, whereas amphetamine is a substrate for the DAT and after binding can reverse the DAT to pump dopamine into the synapse as well as enhance vesicular release of dopamine upon transporter internalization (for review, see Schmitt and Reith, 2010). This high level of dopaminergic signaling in DAT-enriched regions such as the "brain reward pathway," composed of the VTA and NAc, lead to the pleasurable sensation experienced by drug users. In animal models, the effects of cocaine or amphetamine are modeled by behavioral parameters of self-administration, a model of human voluntary drugtaking; locomotor activity after drug application, to assess sensitization to drug application; or the association of drug application with context, or conditioned place preference (CPP).
1. Psychomotor Stimulants Alter Brain-Derived Neurotrophic Factor Levels. Short- and long-term cocaine administration both cause increases in BDNF levels and are associated with intracellular signaling pathways in the brain reward pathway, and these changes persist during drug withdrawal (Corominas et al., 2007; Russo et al., 2009). A single dose of cocaine results in increased BDNF mRNA expression in the NAc shell, but not the NAc core region, the VTA, or the hippocampus (Russo et al., 2009). In addition, BDNF protein expression as well as $\operatorname{TrkB}$ autophosphorylation is augmented in NAc of cocaine self-administering rats (Graham et al., 2007; Graham et al., 2009) (Fig. 4A, B).

Furthermore, plasticity of reward-pathway circuitry is known to be altered by long-term cocaine use. Previous studies have demonstrated increased dendritic arborization accompanied by elevated spine numbers after longterm cocaine administration (Robinson and Kolb, 1999) that correlates to a decreased threshold for LTP in the reward pathway (Corominas et al., 2007). These observations may result from BDNF increases in reward-related brain regions mentioned above (Russo et al., 2009). For this reason, BDNF is widely studied in the changes in behavior, morphology, and gene expression associated with cocaine addiction.

2. Brain-Derived Neurotrophic Factor Infusions Alter Addiction-Related Behaviors. Direct infusion of BDNF into the nigrostriatal and mesolimbic dopaminergic pathway potentiates the stimulating effects of cocaine administration as assessed by locomotor activity (Corominas et al., 2007). Infusion of BDNF into either the NAc or the VTA results in enhanced locomotor sensitization with repeated cocaine administration (Corominas et al., 2007). In a long-term cocaine self-administration model, infusion of BDNF into NAc increases drug intake and drug-seeking behavior, augments drug craving after withdrawal, and enhances cue- and stress-induced reinstatement (Graham et al., 2007). VTA targeted infusion of BDNF during withdrawal also enhances cocaine-seeking behavior (Corominas et al., 2007). Collectively, these data imply a crucial role for $\mathrm{BDNF}$ in facilitating drug-using, drugseeking, and relapse behaviors associated with the brain reward pathway.

3. Brain-Derived Neurotrophic Factor Animal Models Show Altered Addiction-Related Behaviors. Locomotor potentiation after an short-term dose of cocaine is blunted in BDNF heterozygous mice (Corominas et al., 2007). In addition, BDNF heterozygous mice show delayed locomotor sensitization to repeated cocaine administration (Corominas et al., 2007) as well as decreased CPP (Corominas et al., 2007). Localized knockdown of $\mathrm{BDNF}$ in the NAc results in reduced CPP and reduced cocaine-reinforcement of drug-taking, whereas similar viral deletion studies reveal that TrkB seems to be essential for CPP (Graham et al., 2007, 2009). These findings reveal that reduced reward-pathway expression of 

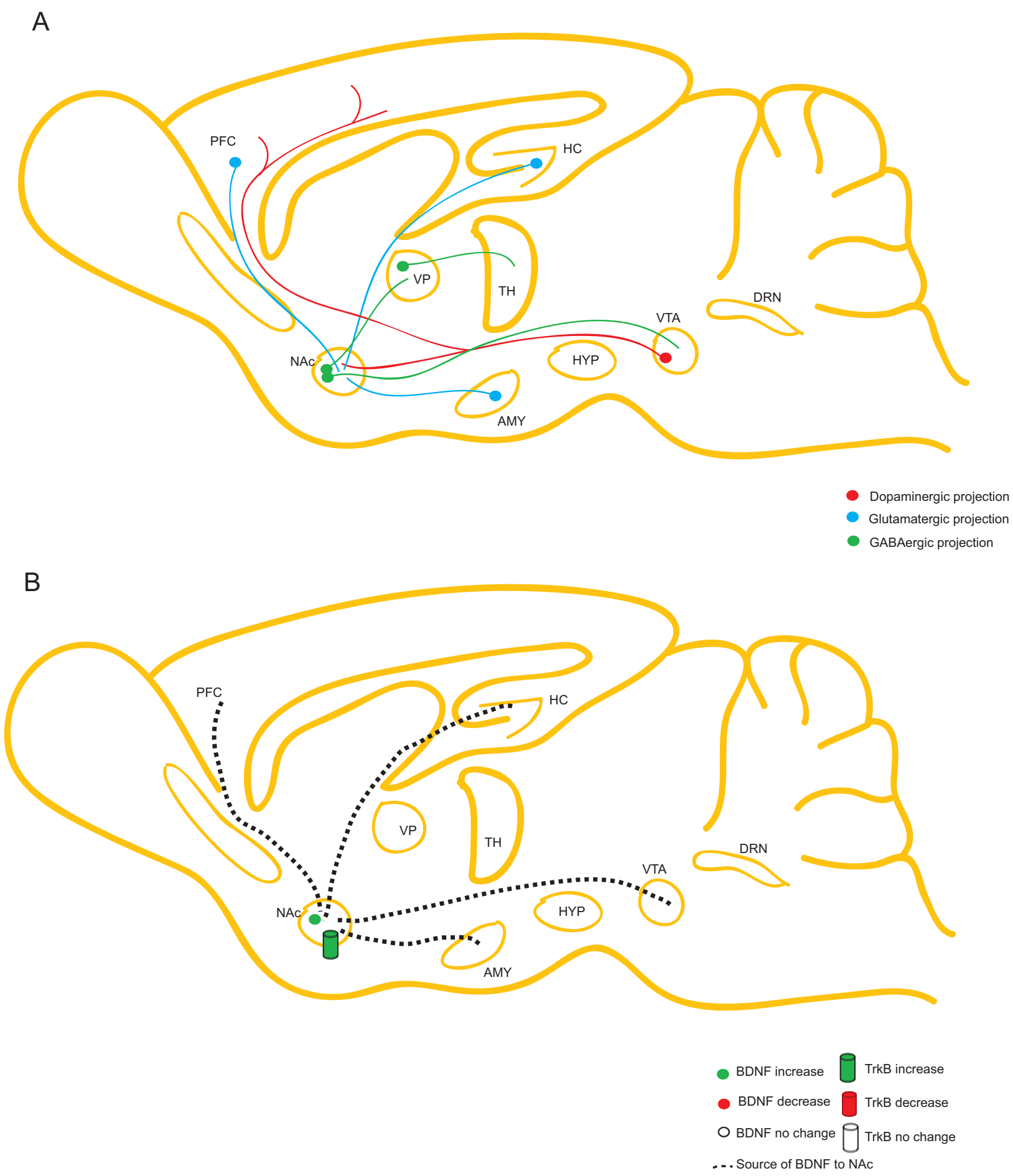

FIG. 4. Schematic of the role of BDNF in the brain reward pathway associated with addiction. A, the brain reward pathway consists of the mesolimbic dopaminergic pathway that projects from the VTA to the NAc. The NAc also receives excitatory input from limbic regions, including the cortex, hippocampus, and amygdala. The NAc in turn sends GABAergic projections to the thalamus via the "direct" and "indirect" pathways. B, addictional research demonstrates that BDNF and TrkB signaling are enhanced in the NAc. Although BDNF mRNA levels are typically low in this area, BDNF may be secreted from limbic regions as well as the VTA. [Adapted from Bolaños CA and Nestler EJ (2004) Neurotrophic mechanisms in drug addiction. Neuromolecular Med 5:69-83. Copyright (C) 2004 Springer. Used with permission.]

BDNF or TrkB results in decreased rewarding effects of cocaine usage.

The effects of BDNF in nucleus accumbens may be mediated through its receptor TrkB in a cell-type specific manner (Lobo et al., 2010). TrkB signaling in NAc neurons expressing D1 dopamine receptor seem to act to dampen rewarding properties of cocaine (Lobo et al., 2010). In contrast, in D2-expressing neurons, TrkB signaling enhances the rewarding properties of cocaine (Lobo et al., 2010). The authors suggest that this difference in modulation is a result of increased cell excitability in the absence of TrkB signaling, which confers opposite effects on circuit level 
activity through D1 or D2 cell effects. Further dissection of these distinct pathways will be necessary to attribute celltype specific effects of BDNF signaling in NAc with respect to cocaine addiction-related behaviors. These data together reveal an essential role for NAc BDNF signaling in the rewarding effects of cocaine and propensity for relapse with a potentially predominant behavioral effect through signaling of D2 receptor-expressing cells.

\section{B. Morphine}

Abuse of opiate substances including morphine, opium, and heroin, is a significant issue because of the high risk for addiction, tolerance, and dependence. Opiates are isolated from the seeds of the poppy plants and their effects include analgesia, sedation, and euphoria. Opiates confer these effects by binding to endogenous opioid receptors divided into $\delta, \kappa$, and $\mu$ subtypes, which are highly enriched in the peripheral and central nervous system (Wittert et al., 1996; Janecka et al., 2004). Like cocaine and amphetamine, morphine addiction involves the "brain reward circuitry," in which BDNF seems to play a prominent role. Intriguingly, human heroin addicts have significantly lower serum levels of BDNF compared with nonaddicts (Angelucci et al., 2007b). For this reason, researchers are interested in studying the role of BDNF in morphine addiction.

1. Morphine Effects on Brain-Derived Neurotrophic Factor Signaling. Animal models examining effects of morphine demonstrate a significant regulation of BDNF. Morphine treatment reduces BDNF expression in VTA neurons (Chu et al., 2007). After withdrawal, there is an immediate increase in BDNF protein expression in VTA followed by a decrease after long-term withdrawal (Chu et al., 2007). BDNF mRNA expression is also enhanced after long-term withdrawal from self-administered heroin (Kuntz-Melcavage et al., 2009). Longterm morphine administration does not seem to affect BDNF or TrkB protein expression in hippocampus (Arguello et al., 2009).

In locus ceruleus, the noradrenergic input to the VTA, long-term morphine treatment in rodents increases bdnf transcript expression by approximately $10 \%$ with no change in trkb expression (Numan et al., 1998). However, during opiate withdrawal, BDNF mRNA expression increases by 2 - to 3 -fold up to 3 days after opiate removal (Numan et al., 1998). This dramatic increase corresponds to enhanced TrkB receptor expression within $6 \mathrm{~h}$ of withdrawal (Numan et al., 1998). These data suggest that BDNF signaling in the locus ceruleus may have an essential role in opiate withdrawal.

2. Effects of Brain-Derived Neurotrophic Factor Infusion on Opiate-Induced Cellular Alterations. A particularly striking effect of chronic morphine in rodent models is decreased VTA dopamine neuron cell size coupled with enhanced tyrosine hydroxylase (TH) expression (Sklair-Tavron et al., 1996). Long-term BDNF infusion into VTA seems to oppose the effect of morphine to increase TH levels and to decrease cell size by causing negative feedback on intracellular ERK expression (Berhow et al., 1995, 1996; Sklair-Tavron et al., 1996).

3. Opiates in Brain-Derived Neurotrophic Factor Models. In postnatal conditional BDNF knockouts, morphine withdrawal responses are attenuated (Akbarian et al., 2002). It is noteworthy that loss of BDNF results in attenuated cell morphology alterations in TH expression after long-term morphine treatment (Akbarian et al., 2002). Taken together with previous data, BDNF expression seems be enhanced during opiate withdrawal, potentially to oppose the effects of long-term morphine administration on VTA dopaminergic cell size decrease. Future studies will be necessary to fully elucidate the relationship of BDNF circuit-level signaling on opiate addiction and withdrawal.

\section{Nicotine and Alcohol}

Cigarette smoking is the leading cause of preventable death in the United States and is responsible for nearly 1 in 5 deaths reported each year (Koop and Luoto, 2006). The addictive compound in cigarette smoke is nicotine, which binds to neuronal nicotinic acetylcholine receptors. Studies of human subjects addicted to cigarette smoking reveal association with several BDNF SNPs (Beuten et al., 2005) including the V66M polymorphism (Lang et al., 2007b) as well as TrkB SNPs (Beuten et al., 2007), suggesting that humans with altered BDNF signaling may be more likely to become addicted and remain addicted to nicotine. A recent meta-analysis suggests that several BDNF SNPs are significantly correlated to initiation of smoking $(\mathrm{Nu}-$ man et al., 1998) Gene interaction studies suggest that a potential explanation for this association may be the influence of BDNF-TrkB signaling on regulation of nicotinic receptor subunits $\alpha 4$ and $\beta 2$ (Li et al., 2008).

Long-term nicotine administration in rodents leads to increased protein expression of BDNF in the cortex and the hippocampus (Czubak et al., 2009). Nicotine enhances TrkB mRNA and protein expression in the cortex and the striatum and decreases TrkB expression in the VTA (Sun et al., 2007). In cultured neuroblastoma cells, nicotine induces BDNF secretion (Serres and Carney, 2006). Taken together, these data suggest that nicotine, via activation of nicotinic receptors, may lead to BDNF release in the cortex and the striatum; similar to effects of cocaine, BDNF-TrkB signaling may enhance the rewarding properties of smoking.

Alcohol dependence is the third leading cause of preventable death in the United States (Mokdad et al., 2004). Chronic alcoholism leads to degeneration of brain tissue and can lead to Wernicke-Korsakoff syndrome in adults. In addition, alcohol consumption by pregnant women can have severe impact on fetal development and can lead to fetal alcohol syndrome. Analysis reveals that there may be significant hereditary regulation of alcohol dependence (Mokdad et al., 2004). Intriguingly, patients with alcohol dependence display reduced serum levels of BDNF (Joe et 
al., 2007). Human studies of BDNF SNPs show that the V66M allele may be important for disease severity (Grzywacz et al., 2010).

In animal studies, there is not a definitive effect of alcohol on BDNF expression in any brain region (for review, see Davis, 2008). In-depth studies focusing on the effects of long-term alcohol use and alcohol withdrawal are necessary to fully understand the impact of alcohol on BDNF-TrkB signaling and how mutations, loss, or overactivation of BDNF signaling pathways may affect alcohol dependence.

\section{Neurodevelopmental Disorders}

\section{A. Rett Syndrome}

Rett syndrome (RTT) is a severe neurodevelopmental disorder characterized by regressive cognitive and language skills with autistic features, respiratory problems, and stereotypical hand-wringing (Hagberg et al., 1983). RTT is an X-linked disorder affecting around 1 in 10,000 live female births (Amaral et al., 2007). RTT is caused by loss of function mutations in MeCP2 (Amir et al., 1999). $\mathrm{MeCP} 2$ binds to methylated $\mathrm{CpG}$ islands, recruits corepressor proteins, and has been classically thought to limit transcription of downstream genes (Lewis et al., 1992; Nan et al., 1998; Adachi et al., 2009) although more recent evidence suggests it may also activate transcription (Yasui et al., 2007; Chahrour et al., 2008). Intriguingly, BDNF is a target of MeCP2 and, given BDNF's role in synaptic plasticity and neuronal development, is of great interest in the study of RTT (Chen et al., 2003a).

Patients with RTT have been reported to show abnormalities in brain structure, primarily shortened dendrites in cortical and limbic regions (Chapleau et al., 2009). Clinical studies have not yet linked structural alterations to changes in BDNF levels in serum or cerebrospinal fluid (Amaral et al., 2007). In mouse models of MeCP2 deletion, it seems that although deletion of this gene does initially increase BDNF expression, BDNF expression decreases over time (Chang et al., 2006). Recent studies have tried to better elucidate the link between MeCP2 and BDNF using mouse transgenic models. The combination of MeCP2 null with deletion of BDNF results in more severe behavioral and synaptic deficits than MeCP2 deletion alone (Chang et al., 2006). Conversely, overexpression of BDNF in MeCP2null mice delays the onset of RTT-associated features (Chang et al., 2006), further suggesting a link between alterations in BDNF levels and MeCP2.

\section{B. Rubinstein-Taybi Syndrome}

Rubinstein-Taybi syndrome (RTS) is a rare illness affecting approximately 1 in 100,000 to 125,000 live births and is associated with mental retardation, delayed growth, and distinct facial features (Roelfsema and Peters, 2007). Inheritance patterns show that the disease is autosomal dominant (Hallam and Bourtchouladze, 2006) and caused by sporadic de novo gene mutations (Roelfsema and Peters,
2007). Clinical studies have identified a multitude of mutations (for review, see Roelfsema and Peters, 2007) in CREB binding protein (CBP) and more recently homolog p300 as causative for $\sim 55 \%$ of patients presenting with this rare syndrome (Hennekam, 2006). It remains unclear whether mutations in CBP lead to loss-of-function or dominant-negative proteins (Hallam and Bourtchouladze, 2006).

CBP and p300 have activity and form complexes with transcription factors to activate gene transcription (Hallam and Bourtchouladze, 2006). Because only $\sim 55 \%$ of patients with RTS have a known mutation, researchers are interested in examining other proteins involved in transcriptional activation associated with RTS (Hennekam, 2006). As mentioned in section I.A, $B D N F$ is a gene with a cAMP response element in its promoter region, and thus is a target of CREB. Intriguingly, mice heterozygous for CBP have impairments in learning and memory tasks accompanied by decreased BDNF transcription (Hallam and Bourtchouladze, 2006). These observations suggest that future study of BDNF's role in symptoms of RTS and its potential as a therapeutic target for treating RTS may be worthwhile to pursue.

\section{Brain-Derived Neurotrophic Factor and Eating Disorders}

Anorexia nervosa (AN) and bulimia nervosa (BN) are the most prevalent eating disorders in the United States and affect up to $3 \%$ of women(Becker et al., 1999). These disorders are associated with distorted attitudes toward weight and body image that result in pathological eating behaviors and inability to maintain a healthy weight (Klein and Walsh, 2004). Studies have revealed a strong genetic contribution to eating disorders. Given the high comorbidity of $\mathrm{AN}$ and $\mathrm{BN}$ with anxiety and depressionlike symptoms (Ivarsson et al., 2000; Thornton et al., 2011), BDNF is a gene of interest in feeding behavior and weight (Rask-Andersen et al., 2010).

\section{A. Animal Studies}

Studies of BDNF animal models have revealed that loss of BDNF results in increased weight. BDNF heterozygous mice display hyperphagia as well as weight gain in early life (Hashimoto et al., 2005a). Likewise, conditional BDNF knockout mice and inducible BDNF KO mice show higher body weight after BDNF deletion (Monteggia et al., 2004; Hashimoto et al., 2005a). This elevation in body weight in conditional BDNF KO mice is associated with increased levels of circulating hormones such as leptin, insulin, glucose, and cholesterol (Hashimoto et al., 2005a). These hormones are linked to increased food intake (Hashimoto et al., 2005a). It is noteworthy that the weight phenotype in BDNF heterozygous mice can be reversed by treatment with fluoxetine or intraventricular infusion of BDNF (Hashimoto et al., 2005a). These data suggest an 
emerging role for BDNF in feeding behavior and weight maintenance.

\section{B. Human Studies}

Clinical studies have studied potential linkage of the known C270T and V66M BDNF polymorphisms to eating disorders. In several patient populations, studies have shown positive correlations between subtypes of $\mathrm{AN}$ and BN to these BDNF alleles. Several European and Japanese studies have demonstrated that the V66M allele is associated with eating disorders (Koizumi et al., 2004; Ribasés et al., 2005; Dmitrzak-Weglarz et al., 2007), particularly with all subtypes of AN and purging-type BN, although this finding is not unequivocal (Friedel et al., 2005; Dardennes et al., 2007; Rybakowski et al., 2007). Only a few patient populations have revealed a correlation between the C270T allele and bulimia nervosa (Ribasés et al., 2004); the majority of data suggest no association with anorexia nervosa or other eating disorders (Ribasés et al., 2005; Rybakowski et al., 2007), leaving uncertain the role of this polymorphism in eating disorder pathophysiology (Hashimoto et al., 2005a).

\section{Brain-Derived Neurotrophic Factor-Based Therapeutics}

As described in this review, BDNF is associated with a multitude of psychiatric disorders. Methods of manipulating BDNF expression and signaling are of great interest for development of novel therapeutics for psychiatric illnesses. However, there are major caveats to targeting BDNF, such as the fact that levels of BDNF are maintained within an optimal range in neurons and also because each disease seems to be associated with brainregion-specific alterations in BDNF. For example, therapies that increase or decrease BDNF levels or signaling activity outside this range, or in incorrect neural circuit regions, may lead to neuronal excitotoxicity, undesired increased growth or survival of tumor cells, or cardiovascular side effects (Price et al., 2007). Another drawback to use of chemical modulators of BDNF signaling is the lack of mechanistic insight into their ability to increase BDNF. As noted in sections II.A and IV.A, many therapies for schizophrenia and depression have indirect effects on BDNF levels (Price et al., 2007), although the mechanism for this modulation is unknown. Furthermore, the use of recombinant BDNF molecules has not been successful in clinical trials because of side effects (Chao et al., 2006), inability to cross the blood-brain barrier with systemic treatment, and complications associated with surgical infusion of proteins directly into the brain (Monteggia, 2011).

To overcome these limitations, efforts have been made to synthesize short peptide sequences that mimic growth factors to more selectively target receptors. BDNF "mimetic" peptides have been developed in the last several years (Yang et al., 2005; Fletcher et al., 2008; Jang et al., 2010). Preclinical studies have yet to fully characterize these
BDNF mimetic peptides, but recent evidence suggests that 7,8-dihydroxyflavone may enhance fear-conditioned memory in rodents (Andero et al., 2011). Further study will be necessary to understand the full potential of these molecules in various disease models and characterize specificity for TrkB receptors.

Recent evidence has suggested that ketamine, a well known anesthetic with NMDA receptor antagonist activity, is effective in very low doses for treatment of both MDD (Berman et al., 2000; Zarate et al., 2006; Price et al., 2009) and BD (Diazgranados et al., 2010). Our laboratory has demonstrated that this drug may elevate protein levels of BDNF through a translational mechanism involving the eukaryotic elongation factor-2 pathway (Autry et al., 2011). Intriguingly, we also observed that use of the eukaryotic elongation factor-2 kinase inhibitors rottlerin and 1-benzyl-3-cetyl-2-methylimidazolium iodide (NH125) resulted in molecular and behavioral effects similar to those of ketamine. These exciting findings suggest that modulation of BDNF at the protein level via a fast-acting translation pathway may offer a clinically applicable mechanism for increasing BDNF in the optimal physiological range.

\section{Conclusions and Future Directions}

By virtue of its critical role in development, synaptic plasticity, and neuronal cell health, BDNF is a vital component to normal brain function. For this reason, it has been studied extensively in relation to psychiatric disorders associated with abnormal brain development and function. It is clear that BDNF has a prominent role in the pathophysiology associated with disorders such as MDD, SZ, BD, anxiety-related disorders, addiction, RTT, and eating disorders. However, future work will be necessary to determine whether BDNF is a risk factor for initiation or maintenance or in the recovery process with respect to each of these distinct disorders and how its circuit-level function contributes at each of these stages. In addition, the search for more effective and applicable BDNF-based therapies is crucial in light of the impact BDNF lends to these disease processes.

\section{Acknowledgments}

This research was supported by the National Institutes of Health National Institute of Mental Health [Grants MH070727, MH081060] (to L.M.M.).

\section{Authorship Contributions \\ Wrote or contributed to the writing of the manuscript: Autry and Monteggia.}

\section{References}

Adachi M, Autry AE, Covington HE 3rd, and Monteggia LM (2009) MeCP2-mediated transcription repression in the basolateral amygdala may underlie heightened anxiety in a mouse model of Rett syndrome. J Neurosci 29:4218-4227.

Adachi M, Barrot M, Autry AE, Theobald D, and Monteggia LM (2008) Selective loss of brain-derived neurotrophic factor in the dentate gyrus attenuates antidepressant efficacy. Biol Psychiatry 63:642-649.

Advani T, Koek W, and Hensler JG (2009) Gender differences in the enhanced vulnerability of BDNF+/- mice to mild stress. Int $J$ Neuropsychopharmacol 12: $583-588$. 
Aid T, Kazantseva A, Piirsoo M, Palm K, and Timmusk T (2007) Mouse and rat BDNF gene structure and expression revisited. J Neurosci Res 85:525-535.

Akbarian S, Rios M, Liu RJ, Gold SJ, Fong HF, Zeiler S, Coppola V, Tessarollo L, Jones KR, Nestler EJ, et al. (2002) Brain-derived neurotrophic factor is essential for opiate-induced plasticity of noradrenergic neurons. J Neurosci 22:4153-4162.

Altar CA, Whitehead RE, Chen R, Wörtwein G, and Madsen TM (2003) Effects of electroconvulsive seizures and antidepressant drugs on brain-derived neurotrophic factor protein in rat brain. Biol Psychiatry 54:703-709.

Amaral MD, Chapleau CA, and Pozzo-Miller L (2007) Transient receptor potential channels as novel effectors of brain-derived neurotrophic factor signaling: potential implications for Rett syndrome. Pharmacol Ther 113:394-409.

Amir RE, Van den Veyver IB, Wan M, Tran CQ, Francke U, and Zoghbi HY (1999) Rett syndrome is caused by mutations in X-linked MECP2, encoding methyl-CpGbinding protein 2. Nat Genet 23:185-188.

Andero R, Heldt SA, Ye K, Liu X, Armario A, and Ressler KJ (2011) Effect of 7,8-dihydroxyflavone, a small-molecule TrkB agonist, on emotional learning. Am J Psychiatry 168:163-172.

Anderson KD, Alderson RF, Altar CA, DiStefano PS, Corcoran TL, Lindsay RM, and Wiegand SJ (1995) Differential distribution of exogenous BDNF, NGF, and NT-3 in the brain corresponds to the relative abundance and distribution of high-affinity and low-affinity neurotrophin receptors. J Comp Neurol 357:296-317.

Angelucci F, Gruber SH, El Khoury A, Tonali PA, and Mathé AA (2007a) Chronic amphetamine treatment reduces NGF and BDNF in the rat brain. Eur Neuropsychopharmacol 17:756-762.

Angelucci F, Ricci V, Pomponi M, Conte G, Mathé AA, Attilio Tonali P, and Bria P (2007b) Chronic heroin and cocaine abuse is associated with decreased serum concentrations of the nerve growth factor and brain-derived neurotrophic factor. J Psychopharmacol 21:820-825.

Arguello AA, Fischer SJ, Schonborn JR, Markus RW, Brekken RA, and Eisch AJ (2009) Effect of chronic morphine on the dentate gyrus neurogenic microenvironment. Neuroscience 159:1003-1010.

Autry AE, Adachi M, Cheng P, and Monteggia LM (2009) Gender-specific impact of brain-derived neurotrophic factor signaling on stress-induced depression-like behavior. Biol Psychiatry 66:84-90.

Autry AE, Adachi M, Nosyreva E, Na ES, Los MF, Cheng PF, Kavalali ET, and Monteggia LM (2011) NMDA receptor blockade at rest triggers rapid behavioural antidepressant responses. Nature 475:91-95.

Balu DT, Hoshaw BA, Malberg JE, Rosenzweig-Lipson S, Schechter LE, and Lucki I (2008) Differential regulation of central BDNF protein levels by antidepressant and non-antidepressant drug treatments. Brain Res 1211:37-43.

Barde YA, Edgar D, and Thoenen H (1982) Purification of a new neurotrophic factor from mammalian brain. EMBO J 1:549-553.

Becker AE, Grinspoon SK, Klibanski A, and Herzog DB (1999) Eating disorders. N Engl J Med 340:1092-1098.

Becker JB, Monteggia LM, Perrot-Sinal TS, Romeo RD, Taylor JR, Yehuda R, and Bale TL (2007) Stress and disease: is being female a predisposing factor? J Neurosci 27:11851-11855.

Berhow MT, Hiroi N, and Nestler EJ (1996) Regulation of ERK (extracellular signal regulated kinase), part of the neurotrophin signal transduction cascade, in the rat mesolimbic dopamine system by chronic exposure to morphine or cocaine. J Neurosci 16:4707-4715.

Berhow MT, Russell DS, Terwilliger RZ, Beitner-Johnson D, Self DW, Lindsay RM, and Nestler EJ (1995) Influence of neurotrophic factors on morphine- and cocaineinduced biochemical changes in the mesolimbic dopamine system. Neuroscience 68:969-979.

Berman RM, Cappiello A, Anand A, Oren DA, Heninger GR, Charney DS, and Krystal JH (2000) Antidepressant effects of ketamine in depressed patients. Biol Psychiatry 47:351-354.

Berton O, McClung CA, Dileone RJ, Krishnan V, Renthal W, Russo SJ, Graham D, Tsankova NM, Bolanos CA, Rios M, et al. (2006) Essential role of BDNF in the mesolimbic dopamine pathway in social defeat stress. Science 311:864-868.

Beuten J, Ma JZ, Payne TJ, Dupont RT, Lou XY, Crews KM, Elston RC, and Li MD (2007) Association of specific haplotypes of neurotrophic tyrosine kinase receptor 2 gene (NTRK2) with vulnerability to nicotine dependence in African-Americans and European-Americans. Biol Psychiatry 61:48-55.

Beuten J, Ma JZ, Payne TJ, Dupont RT, Quezada P, Huang W, Crews KM, and Li MD (2005) Significant association of BDNF haplotypes in European-American male smokers but not in European-American female or African-American smokers. Am J Med Genet B Neuropsychiatr Genet 139B:73-80.

Blum R, Kafitz KW, and Konnerth A (2002) Neurotrophin-evoked depolarization requires the sodium channel $\mathrm{Na}(\mathrm{V}) 1.9$. Nature 419:687-693.

Boos HB, Aleman A, Cahn W, Hulshoff Pol H, and Kahn RS (2007) Brain volumes in relatives of patients with schizophrenia: a meta-analysis. Arch Gen Psychiatry 64:297-304.

Bremner JD, Narayan M, Anderson ER, Staib LH, Miller HL, and Charney DS (2000) Hippocampal volume reduction in major depression. Am J Psychiatry 157: $115-118$.

Büttner A (2011) Review: the neuropathology of drug abuse. Neuropathol Appl Neurobiol 37:118-134.

Castrén E (2004) Neurotrophic effects of antidepressant drugs. Curr Opin Pharmacol 4:58-64.

Castrén E and Rantamäki T (2010) The role of BDNF and its receptors in depression and antidepressant drug action: Reactivation of developmental plasticity. Dev Neurobiol 70:289-297.

Castrén E, Võikar V, and Rantamäki T (2007) Role of neurotrophic factors in depression. Curr Opin Pharmacol 7:18-21.

Chahrour M, Jung SY, Shaw C, Zhou X, Wong ST, Qin J, and Zoghbi HY (2008) $\mathrm{MeCP} 2$, a key contributor to neurological disease, activates and represses transcription. Science 320:1224-1229.

Chang Q, Khare G, Dani V, Nelson S, and Jaenisch R (2006) The disease progression of Mecp2 mutant mice is affected by the level of BDNF expression. Neuron 49:341-348.

Chao MV, Rajagopal R, and Lee FS (2006) Neurotrophin signalling in health and disease. Clin Sci (Lond) 110:167-173.

Chapleau CA, Calfa GD, Lane MC, Albertson AJ, Larimore JL, Kudo S, Armstrong DL, Percy AK, and Pozzo-Miller L (2009) Dendritic spine pathologies in hippocampal pyramidal neurons from Rett syndrome brain and after expression of Rettassociated MECP2 mutations. Neurobiol Dis 35:219-233.

Charney DS and Manji HK (2004) Life stress, genes, and depression: multiple pathways lead to increased risk and new opportunities for intervention. Sci STKE 2004:re5.

Chen G and Manji HK (2006) The extracellular signal-regulated kinase pathway: an emerging promising target for mood stabilizers. Curr Opin Psychiatry 19:313-323 Chen WG, Chang Q, Lin Y, Meissner A, West AE, Griffith EC, Jaenisch R, and Greenberg ME (2003a) Derepression of BDNF transcription involves calciumdependent phosphorylation of MeCP2. Science 302:885-889.

Chen WG, West AE, Tao X, Corfas G, Szentirmay MN, Sawadogo M, Vinson C, and Greenberg ME (2003b) Upstream stimulatory factors are mediators of $\mathrm{Ca} 2+$ responsive transcription in neurons. J Neurosci 23:2572-2581.

Chen ZY, Jing D, Bath KG, Ieraci A, Khan T, Siao CJ, Herrera DG, Toth M, Yang C McEwen BS, et al. (2006) Genetic variant BDNF (Val66Met) polymorphism alters anxiety-related behavior. Science 314:140-143.

Chourbaji S, Hellweg R, Brandis D, Zörner B, Zacher C, Lang UE, Henn FA Hörtnagl H, and Gass P (2004) Mice with reduced brain-derived neurotrophic factor expression show decreased choline acetyltransferase activity, but regula brain monoamine levels and unaltered emotional behavior. Brain Res Mol Brain Res 121:28-36.

Chu NN, Zuo YF, Meng L, Lee DY, Han JS, and Cui CL (2007) Peripheral electrical stimulation reversed the cell size reduction and increased BDNF level in the ventral tegmental area in chronic morphine-treated rats. Brain Res 1182:90-98.

Corominas M, Roncero C, Ribases M, Castells X, and Casas M (2007) Brain-derived neurotrophic factor and its intracellular signaling pathways in cocaine addiction. Neuropsychobiology 55:2-13.

Cowansage KK, LeDoux JE, and Monfils MH (2010) Brain-derived neurotrophic factor: a dynamic gatekeeper of neural plasticity. Curr Mol Pharmacol 3:12-29.

Czubak A, Nowakowska E, Kus K, Burda K, Metelska J, Baer-Dubowska W, and Cichocki M (2009) Influences of chronic venlafaxine, olanzapine and nicotine on the hippocampal and cortical concentrations of brain-derived neurotrophic factor (BDNF). Pharmacol Rep 61:1017-1023

Dardennes RM, Zizzari P, Tolle V, Foulon C, Kipman A, Romo L, Iancu-Gontard D Boni C, Sinet PM, Thérèse Bluet M, et al. (2007) Family trios analysis of common polymorphisms in the obestatin/ghrelin, BDNF and AGRP genes in patients with Anorexia nervosa: association with subtype, body-mass index, severity and age of onset. Psychoneuroendocrinology 32:106-113

Davis MI (2008) Ethanol-BDNF interactions: still more questions than answers Pharmacol Ther 118:36-57.

Daws LC, Munn JL, Valdez MF, Frosto-Burke T, and Hensler JG (2007) Serotonin transporter function, but not expression, is dependent on brain-derived neurotrophic factor (BDNF): in vivo studies in BDNF-deficient mice. J Neurochem 101:641-651.

Deltheil T, Guiard BP, Cerdan J, David DJ, Tanaka KF, Repérant C, Guilloux JP, Coudoré F, Hen R, and Gardier AM (2008a) Behavioral and serotonergic consequences of decreasing or increasing hippocampus brain-derived neurotrophic factor protein levels in mice. Neuropharmacology 55:1006-1014.

Deltheil T, Guiard BP, Guilloux JP, Nicolas L, Deloménie C, Repérant C, Le Maitre E, Leroux-Nicollet I, Benmansour S, Coudoré F, et al. (2008b) Consequences of changes in BDNF levels on serotonin neurotransmission, 5-HT transporter expression and function: studies in adult mice hippocampus. Pharmacol Biochem Behav 90:174-183.

Di Luca M, Caputi A, and Cattabeni F (1994) Synaptic protein phosphorylation changes in animals exposed to neurotoxicants during development. Neurotoxicology 15:525-532.

Diazgranados N, Ibrahim L, Brutsche NE, Newberg A, Kronstein P, Khalife S, Kammerer WA, Quezado Z, Luckenbaugh DA, Salvadore G, et al. (2010) A randomized add-on trial of an $N$-methyl-D-aspartate antagonist in treatmentresistant bipolar depression. Arch Gen Psychiatry 67:793-802.

Dluzen DE, Gao X, Story GM, Anderson LI, Kucera J, and Walro JM (2001) Evaluation of nigrostriatal dopaminergic function in adult $+/+$ and $+/$ - BDNF mutan mice. Exp Neurol 170:121-128.

Dmitrzak-Weglarz M, Skibinska M, Slopien A, Szczepankiewicz A, Rybakowski F, Kramer L, Hauser J, and Rajewski A (2007) BDNF Met66 allele is associated with anorexia nervosa in the Polish population. Psychiatr Genet 17:245-246.

Drevets WC and Furey ML (2010) Replication of scopolamine's antidepressant efficacy in major depressive disorder: a randomized, placebo-controlled clinical trial Biol Psychiatry 67:432-438.

Duman RS and Monteggia LM (2006) A neurotrophic model for stress-related mood disorders. Biol Psychiatry 59:1116-1127.

Duman RS, Nakagawa S, and Malberg J (2001) Regulation of adult neurogenesis by antidepressant treatment. Neuropsychopharmacology 25:836-844.

Durany N, Michel T, Zöchling R, Boissl KW, Cruz-Sánchez FF, Riederer P, and Thome J (2001) Brain-derived neurotrophic factor and neurotrophin 3 in schizophrenic psychoses. Schizophr Res 52:79-86.

Durany N and Thome J (2004) Neurotrophic factors and the pathophysiology of schizophrenic psychoses. Eur Psychiatry 19:326-337.

Dwivedi Y (2010) Brain-derived neurotrophic factor and suicide pathogenesis. Ann Med 42:87-96.

Dwivedi Y, Rizavi HS, Conley RR, Roberts RC, Tamminga CA, and Pandey GN (2003) Altered gene expression of brain-derived neurotrophic factor and receptor tyrosine kinase B in postmortem brain of suicide subjects. Arch Gen Psychiatry 60:804-815

Egan MF, Kojima M, Callicott JH, Goldberg TE, Kolachana BS, Bertolino A, Zaitsev 
E, Gold B, Goldman D, Dean M, et al. (2003) The BDNF val66met polymorphism affects activity-dependent secretion of BDNF and human memory and hippocampal function. Cell 112:257-269.

Ellison G (1994) Stimulant-induced psychosis, the dopamine theory of schizophrenia, and the habenula. Brain Res Brain Res Rev 19:223-239.

Ernfors P, Lee KF, and Jaenisch R (1994) Mice lacking brain-derived neurotrophic factor develop with sensory deficits. Nature 368:147-150.

Featherstone RE, Kapur S, and Fletcher PJ (2007) The amphetamine-induced sensitized state as a model of schizophrenia. Prog Neuropsychopharmacol Biol Psychiatry 31:1556-1571.

Fiore M, Korf J, Antonelli A, Talamini L, and Aloe L (2002) Long-lasting effects of prenatal MAM treatment on water maze performance in rats: associations with altered brain development and neurotrophin levels. Neurotoxicol Teratol 24:179 191.

Fletcher JM, Morton CJ, Zwar RA, Murray SS, O'Leary PD, and Hughes RA (2008) Design of a conformationally defined and proteolytically stable circular mimetic of brain-derived neurotrophic factor. J Biol Chem 283:33375-33383.

Friedel S, Horro FF, Wermter AK, Geller F, Dempfle A, Reichwald K, Smidt J, Brönner G, Konrad K, Herpertz-Dahlmann B, et al. (2005) Mutation screen of the brain derived neurotrophic factor gene (BDNF): identification of several genetic variants and association studies in patients with obesity, eating disorders, and attention-deficit/hyperactivity disorder. Am J Med Genet B Neuropsychiatr Genet 132B:96-99.

Frielingsdorf H, Bath KG, Soliman F, Difede J, Casey BJ, and Lee FS (2010) Variant brain-derived neurotrophic factor Val66Met endophenotypes: implications for posttraumatic stress disorder. Ann NY Acad Sci 1208:150-157.

Frodl T, Meisenzahl E, Zetzsche T, Bottlender R, Born C, Groll C, Jäger M, Leinsinger G, Hahn K, and Möller HJ (2002) Enlargement of the amygdala in patients with a first episode of major depression. Biol Psychiatry 51:708-714.

Frustaci A, Pozzi G, Gianfagna F, Manzoli L, and Boccia S (2008) Meta-analysis of the brain-derived neurotrophic factor gene (BDNF) Val66Met polymorphism in anxiety disorders and anxiety-related personality traits. Neuropsychobiology 58: $163-170$.

Furey ML and Drevets WC (2006) Antidepressant efficacy of the antimuscarinic drug scopolamine: a randomized, placebo-controlled clinical trial. Arch Gen Psychiatry 63:1121-1129

Gardier AM (2009) Mutant mouse models and antidepressant drug research: focus on serotonin and brain-derived neurotrophic factor. Behav Pharmacol 20:18-32.

Gatt JM, Nemeroff CB, Dobson-Stone C, Paul RH, Bryant RA, Schofield PR, Gordon $\mathrm{E}$, Kemp AH, and Williams LM (2009) Interactions between BDNF Val66Met polymorphism and early life stress predict brain and arousal pathways to syndromal depression and anxiety. Mol Psychiatry 14:681-695.

Gingrich JA and Hen R (2001) Dissecting the role of the serotonin system in neuropsychiatric disorders using knockout mice. Psychopharmacology (Berl) 155: $1-10$.

Glorioso C, Sabatini M, Unger T, Hashimoto T, Monteggia LM, Lewis DA, and Mirnics K (2006) Specificity and timing of neocortical transcriptome changes in response to BDNF gene ablation during embryogenesis or adulthood. Mol Psychiatry 11:633-648.

Goghari VM, Sponheim SR, and MacDonald AW 3rd (2010) The functional neuroanatomy of symptom dimensions in schizophrenia: a qualitative and quantitative review of a persistent question. Neurosci Biobehav Rev 34(3):468-486.

Gorski JA, Balogh SA, Wehner JM, and Jones KR (2003) Learning deficits in forebrain-restricted brain-derived neurotrophic factor mutant mice. Neuroscience 121:341-354

Graham DL, Edwards S, Bachtell RK, DiLeone RJ, Rios M, and Self DW (2007) Dynamic BDNF activity in nucleus accumbens with cocaine use increases selfadministration and relapse. Nat Neurosci 10:1029-1037.

Graham DL, Krishnan V, Larson EB, Graham A, Edwards S, Bachtell RK, Simmons D, Gent LM, Berton O, Bolanos CA, et al. (2009) Tropomyosin-related kinase B in the mesolimbic dopamine system: region-specific effects on cocaine reward. Biol Psychiatry 65:696-701.

Grzywacz A, Samochowiec A, Ciechanowicz A, and Samochowiec J (2010) Familybased study of brain-derived neurotrophic factor (BDNF) gene polymorphism in alcohol dependence. Pharmacol Rep 62:938-941.

Hagberg B, Aicardi J, Dias K, and Ramos O (1983) A progressive syndrome of autism, dementia, ataxia, and loss of purposeful hand use in girls: Rett's syndrome: report of 35 cases. Ann Neurol 14:471-479.

Hallam TM and Bourtchouladze R (2006) Rubinstein-Taybi syndrome: molecular findings and therapeutic approaches to improve cognitive dysfunction. Cell $\mathrm{Mol}$ Life Sci 63:1725-1735.

Hashimoto K, Koizumi H, Nakazato M, Shimizu E, and Iyo M (2005a) Role of brain-derived neurotrophic factor in eating disorders: recent findings and its pathophysiological implications. Prog Neuropsychopharmacol Biol Psychiatry 29: 499-504

Hashimoto R, Takei N, Shimazu K, Christ L, Lu B, and Chuang DM (2002) Lithium induces brain-derived neurotrophic factor and activates TrkB in rodent cortical neurons: an essential step for neuroprotection against glutamate excitotoxicity. Neuropharmacology 43:1173-1179.

Hashimoto T, Bergen SE, Nguyen QL, Xu B, Monteggia LM, Pierri JN, Sun Z Sampson AR, and Lewis DA (2005b) Relationship of brain-derived neurotrophic factor and its receptor TrkB to altered inhibitory prefrontal circuitry in schizophrenia. J Neurosci 25:372-383.

Heinz A and Schlagenhauf F (2010) Dopaminergic dysfunction in schizophrenia: salience attribution revisited. Schizophr Bull 36:472-485.

Heldt SA, Stanek L, Chhatwal JP, and Ressler KJ (2007) Hippocampus-specific deletion of BDNF in adult mice impairs spatial memory and extinction of aversive memories. Mol Psychiatry 12:656-670.

Hennekam RC (2006) Rubinstein-Taybi syndrome. Eur J Hum Genet 14:981-985.

Hensler JG, Advani T, and Monteggia LM (2007) Regulation of serotonin-1A receptor function in inducible brain-derived neurotrophic factor knockout mice after administration of corticosterone. Biol Psychiatry 62:521-529.

Heymach JV Jr, Krüttgen A, Suter U, and Shooter EM (1996) The regulated secretion and vectorial targeting of neurotrophins in neuroendocrine and epithelial cells. J Biol Chem 271:25430-25437.

Hill JJ, Kolluri N, Hashimoto T, Wu Q, Sampson AR, Monteggia LM, and Lewis DA (2005) Analysis of pyramidal neuron morphology in an inducible knockout of brain-derived neurotrophic factor. Biol Psychiatry 57:932-934.

Hohn A, Leibrock J, Bailey K, and Barde YA (1990) Identification and characterization of a novel member of the nerve growth factor/brain-derived neurotrophic factor family. Nature 344:339-341.

Holick KA, Lee DC, Hen R, and Dulawa SC (2008) Behavioral effects of chronic fluoxetine in BALB/cJ mice do not require adult hippocampal neurogenesis or the serotonin 1A receptor. Neuropsychopharmacology 33:406-417.

Hoshaw BA, Malberg JE, and Lucki I (2005) Central administration of IGF-I and BDNF leads to long-lasting antidepressant-like effects. Brain Res 1037:204-208. Hovatta I and Barlow C (2008) Molecular genetics of anxiety in mice and men. Ann Med 40:92-109.

Hu Y and Russek SJ (2008) BDNF and the diseased nervous system: a delicate balance between adaptive and pathological processes of gene regulation. J Neurochem 105:1-17.

Ibarguen-Vargas Y, Surget A, Vourc'h P, Leman S, Andres CR, Gardier AM, and Belzung C (2009) Deficit in BDNF does not increase vulnerability to stress but dampens antidepressant-like effects in the unpredictable chronic mild stress. Behav Brain Res 202:245-251.

Iritani S, Niizato K, Nawa H, Ikeda K, and Emson PC (2003) Immunohistochemical study of brain-derived neurotrophic factor and its receptor, TrkB, in the hippocampal formation of schizophrenic brains. Prog Neuropsychopharmacol Biol Psychiatry 27:801-807.

Ivarsson T, Råstam M, Wentz E, Gillberg IC, and Gillberg C (2000) Depressive disorders in teenage-onset anorexia nervosa: a controlled longitudinal, partly community-based study. Compr Psychiatry 41:398-403.

Jacobsen JP and Mørk A (2006) Chronic corticosterone decreases brain-derived neurotrophic factor (BDNF) mRNA and protein in the hippocampus, but not in the frontal cortex, of the rat. Brain Res 1110:221-225.

Janecka A, Fichna J, and Janecki T (2004) Opioid receptors and their ligands. Curr Top Med Chem 4:1-17.

Jang SW, Liu X, Yepes M, Shepherd KR, Miller GW, Liu Y, Wilson WD, Xiao G, Blanchi B, Sun YE, et al. (2010) A selective TrkB agonist with potent neurotrophic activities by 7,8-dihydroxyflavone. Proc Natl Acad Sci USA 107:2687-2692.

Javitt DC (2010) Glutamatergic theories of schizophrenia. Isr J Psychiatry Relat Sci 47:4-16.

Joe KH, Kim YK, Kim TS, Roh SW, Choi SW, Kim YB, Lee HJ, and Kim DJ (2007) Decreased plasma brain-derived neurotrophic factor levels in patients with alcohol dependence. Alcohol Clin Exp Res 31:1833-1838.

Jönsson EG, Edman-Ahlbom B, Sillén A, Gunnar A, Kulle B, Frigessi A, Vares M, Ekholm B, Wode-Helgodt B, Schumacher J, et al. (2006) Brain-derived neurotrophic factor gene (BDNF) variants and schizophrenia: an association study Prog Neuropsychopharmacol Biol Psychiatry 30:924-933.

Kang H and Schuman EM (1996) A requirement for local protein synthesis in neurotrophin-induced hippocampal synaptic plasticity. Science 273:1402-1406.

Kernie SG, Liebl DJ, and Parada LF (2000) BDNF regulates eating behavior and locomotor activity in mice. EMBO $J$ 19:1290-1300.

Kessler RC, Chiu WT, Demler O, Merikangas KR, and Walters EE (2005) Prevalence, severity, and comorbidity of 12-month DSM-IV disorders in the National Comorbidity Survey Replication. Arch Gen Psychiatry 62:617-627.

Klein DA and Walsh BT (2004) Eating disorders: clinical features and pathophysiology. Physiol Behav 81:359-374.

Knable MB, Barci BM, Webster MJ, Meador-Woodruff J, and Torrey EF (2004) Molecular abnormalities of the hippocampus in severe psychiatric illness: postmortem findings from the Stanley Neuropathology Consortium. Mol Psychiatr 9:609-620.

Koizumi H, Hashimoto K, Itoh K, Nakazato M, Shimizu E, Ohgake S, Koike K, Okamura N, Matsushita S, Suzuki K, et al. (2004) Association between the brainderived neurotrophic factor 196G/A polymorphism and eating disorders. Am J Med Genet B Neuropsychiatr Genet 127B:125-127.

Koop CE and Luoto J (2006) "The health consequences of smoking: cancer," overview of a report of the Surgeon General. 1982. Public Health Rep 121 (Suppl 1):269275; discussion 268

Kossel AH, Cambridge SB, Wagner U, and Bonhoeffer T (2001) A caged Ab reveals an immediate/instructive effect of BDNF during hippocampal synaptic potentiation. Proc Natl Acad Sci USA 98:14702-14707.

Kovalchuk Y, Holthoff K, and Konnerth A (2004) Neurotrophin action on a rapid timescale. Curr Opin Neurobiol 14:558-563.

Krishnan V, Han MH, Graham DL, Berton O, Renthal W, Russo SJ, Laplant Q, Graham A, Lutter M, Lagace DC, et al. (2007) Molecular adaptations underlying susceptibility and resistance to social defeat in brain reward regions. Cell 131: 391-404.

Kuntz-Melcavage KL, Brucklacher RM, Grigson PS, Freeman WM, and Vrana KE (2009) Gene expression changes following extinction testing in a heroin behavioral incubation model. BMC Neurosci 10:95.

Lang UE, Puls I, Muller DJ, Strutz-Seebohm N, and Gallinat J (2007a) Molecular mechanisms of schizophrenia. Cell Physiol Biochem 20:687-702.

Lang UE, Sander T, Lohoff FW, Hellweg R, Bajbouj M, Winterer G, and Gallinat J (2007b) Association of the met66 allele of brain-derived neurotrophic factor (BDNF) with smoking. Psychopharmacology (Berl) 190:433-439.

Lee R, Kermani P, Teng KK, and Hempstead BL (2001) Regulation of cell survival by secreted proneurotrophins. Science 294:1945-1948.

Lessmann V, Gottmann K, and Malcangio M (2003) Neurotrophin secretion: current facts and future prospects. Prog Neurobiol 69:341-374. 
Levi-Montalcini R (1966) The nerve growth factor: its mode of action on sensory and sympathetic nerve cells. Harvey Lect 60:217-259.

Levine ES, Crozier RA, Black IB, and Plummer MR (1998) Brain-derived neurotrophic factor modulates hippocampal synaptic transmission by increasing Nmethyl-D-aspartic acid receptor activity. Proc Natl Acad Sci USA 95:10235-10239.

Levine ES, Dreyfus CF, Black IB, and Plummer MR (1995) Brain-derived neurotrophic factor rapidly enhances synaptic transmission in hippocampal neurons via postsynaptic tyrosine kinase receptors. Proc Natl Acad Sci USA 92:80748077

Lewis JD, Meehan RR, Henzel WJ, Maurer-Fogy I, Jeppesen P, Klein F, and Bird A (1992) Purification, sequence, and cellular localization of a novel chromosomal protein that binds to methylated DNA. Cell 69:905-914.

Li MD, Lou XY, Chen G, Ma JZ, and Elston RC (2008) Gene-gene interactions among CHRNA4, CHRNB2, BDNF, and NTRK2 in nicotine dependence. Biol Psychiatry 64:951-957.

Lippmann M, Bress A, Nemeroff CB, Plotsky PM, and Monteggia LM (2007) Longterm behavioural and molecular alterations associated with maternal separation in rats. Eur $J$ Neurosci 25:3091-3098.

Liu IY, Lyons WE, Mamounas LA, and Thompson RF (2004) Brain-derived neurotrophic factor plays a critical role in contextual fear conditioning. $J$ Neurosci 24:7958-7963.

Liu QR, Lu L, Zhu XG, Gong JP, Shaham Y, and Uhl GR (2006) Rodent BDNF genes, novel promoters, novel splice variants, and regulation by cocaine. Brain Res 1067:1-12.

Liu QR, Walther D, Drgon T, Polesskaya O, Lesnick TG, Strain KJ, de Andrade M, Bower JH, Maraganore DM, and Uhl GR (2005) Human brain derived neurotrophic factor (BDNF) genes, splicing patterns, and assessments of associations with substance abuse and Parkinson's Disease. Am J Med Genet B Neuropsychiatr Genet 134B:93-103.

Lobo MK, Covington HE 3rd, Chaudhury D, Friedman AK, Sun H, Damez-Werno D, Dietz DM, Zaman S, Koo JW, Kennedy PJ, et al. (2010) Cell type-specific loss of BDNF signaling mimics optogenetic control of cocaine reward. Science 330:385390.

Lodge DJ and Grace AA (2008) Hippocampal dysfunction and disruption of dopamine system regulation in an animal model of schizophrenia. Neurotox Res 14:97-104.

Lohof AM, Ip NY, and Poo MM (1993) Potentiation of developing neuromuscular synapses by the neurotrophins NT-3 and BDNF. Nature 363:350-353.

Lohoff FW, Sander T, Ferraro TN, Dahl JP, Gallinat J, and Berrettini WH (2005) Confirmation of association between the Val66Met polymorphism in the brainderived neurotrophic factor (BDNF) gene and bipolar I disorder. Am J Med Genet $B$ Neuropsychiatr Genet 139B(1):51-53.

$\mathrm{Lu}$ Y, Christian K, and Lu B (2008) BDNF: a key regulator for protein synthesisdependent LTP and long-term memory? Neurobiol Learn Mem 89:312-323.

Lyons WE, Mamounas LA, Ricaurte GA, Coppola V, Reid SW, Bora SH, Wihler C, Koliatsos VE, and Tessarollo L (1999) Brain-derived neurotrophic factor-deficient mice develop aggressiveness and hyperphagia in conjunction with brain serotonergic abnormalities. Proc Natl Acad Sci USA 96:15239-15244.

Malberg JE and Blendy JA (2005) Antidepressant action: to the nucleus and beyond. Trends Pharmacol Sci 26:631-638.

Martinowich K, Hattori D, Wu H, Fouse S, He F, Hu Y, Fan G, and Sun YE (2003) DNA methylation-related chromatin remodeling in activity-dependent BDNF gene regulation. Science 302:890-893.

Martinowich K, Manji H, and Lu B (2007) New insights into BDNF function in depression and anxiety. Nat Neurosci 10:1089-1093.

Matsumoto T, Rauskolb S, Polack M, Klose J, Kolbeck R, Korte M, and Barde YA (2008) Biosynthesis and processing of endogenous BDNF: CNS neurons store and secrete BDNF, not pro-BDNF. Nat Neurosci 11:131-133.

Mattson MP (2008) Glutamate and neurotrophic factors in neuronal plasticity and disease. Ann N Y Acad Sci 1144:97-112.

McEwen BS (2005) Glucocorticoids, depression, and mood disorders: structural remodeling in the brain. Metabolism 54 (5 Suppl 1):20-23

McEwen BS and Magarinos AM (1997) Stress effects on morphology and function of the hippocampus. Ann NY Acad Sci 821:271-284.

Merlio JP, Ernfors P, Jaber M, and Persson H (1992) Molecular cloning of rat trkC and distribution of cells expressing messenger RNAs for members of the trk family in the rat central nervous system. Neuroscience 51:513-532.

Mokdad AH, Marks JS, Stroup DF, and Gerberding JL (2004) Actual causes of death in the United States, 2000. JAMA 291:1238-1245.

Montag C, Basten U, Stelzel C, Fiebach CJ, and Reuter M (2010) The BDNF Val66Met polymorphism and anxiety: support for animal knock-in studies from a genetic association study in humans. Psychiatry Res 179:86-90.

Monteggia LM (2011) Toward neurotrophin-based therapeutics. Am J Psychiatry 168: $114-116$.

Monteggia LM, Barrot M, Powell CM, Berton O, Galanis V, Gemelli T, Meuth S, Nagy A, Greene RW, and Nestler EJ (2004) Essential role of brain-derived neurotrophic factor in adult hippocampal function. Proc Natl Acad Sci USA 101: 10827-10832.

Monteggia LM, Luikart B, Barrot M, Theobold D, Malkovska I, Nef S, Parada LF, and Nestler EJ (2007) Brain-derived neurotrophic factor conditional knockouts show gender differences in depression-related behaviors. Biol Psychiatry 61:187197.

Mössner R, Daniel S, Albert D, Heils A, Okladnova O, Schmitt A, and Lesch KP (2000) Serotonin transporter function is modulated by brain-derived neurotrophic factor (BDNF) but not nerve growth factor (NGF). Neurochem Int 36:197-202.

Mueser KT and McGurk SR (2004) Schizophrenia. Lancet 363:2063-2072.

Nagappan G and Lu B (2005) Activity-dependent modulation of the BDNF receptor TrkB: mechanisms and implications. Trends Neurosci 28:464-471.

Nan X, Ng HH, Johnson CA, Laherty CD, Turner BM, Eisenman RN, and Bird A (1998) Transcriptional repression by the methyl-CpG-binding protein MeCP2 involves a histone deacetylase complex. Nature 393:386-389.

Nanko S, Kunugi H, Hirasawa H, Kato N, Nabika T, and Kobayashi S (2003)
Brain-derived neurotrophic factor gene and schizophrenia: polymorphism screening and association analysis. Schizophr Res 62:281-283.

Naoe Y, Shinkai T, Hori H, Fukunaka Y, Utsunomiya K, Sakata S, Matsumoto C, Shimizu K, Hwang R, Ohmori O, et al. (2007) No association between the brainderived neurotrophic factor (BDNF) Val66Met polymorphism and schizophrenia in Asian populations: Evidence from a case-control study and meta-analysis. Neurosci Lett 415:108-112.

Neves-Pereira M, Mundo E, Muglia P, King N, Macciardi F, and Kennedy JL (2002) The brain-derived neurotrophic factor gene confers susceptibility to bipolar disorder: evidence from a family-based association study. Am J Hum Genet 71:651-655

Nibuya M, Morinobu S, and Duman RS (1995) Regulation of BDNF and trkB mRNA in rat brain by chronic electroconvulsive seizure and antidepressant drug treatments. J Neurosci 15:7539-7547.

Numan S, Lane-Ladd SB, Zhang L, Lundgren KH, Russell DS, Seroogy KB, and Nestler EJ (1998) Differential regulation of neurotrophin and trk receptor mRNAs in catecholaminergic nuclei during chronic opiate treatment and withdrawal $J$ Neurosci 18:10700-10708

Numata S, Ueno S, Iga J, Yamauchi K, Hongwei S, Ohta K, Kinouchi S, ShibuyaTayoshi S, Tayoshi S, Aono M, et al. (2006) Brain-derived neurotrophic facto (BDNF) Val66Met polymorphism in schizophrenia is associated with age at onset and symptoms. Neurosci Lett 401:1-5.

Pandey GN, Ren X, Rizavi HS, Conley RR, Roberts RC, and Dwivedi Y (2008) Brain-derived neurotrophic factor and tyrosine kinase B receptor signalling in post-mortem brain of teenage suicide victims. Int $J$ Neuropsychopharmacol 11 1047-1061.

Patterson SL, Abel T, Deuel TA, Martin KC, Rose JC, and Kandel ER (1996) Recombinant BDNF rescues deficits in basal synaptic transmission and hippocampal LTP in BDNF knockout mice. Neuron 16:1137-1145.

Pillai A (2008) Brain-derived neurotropic factor/TrkB signaling in the pathogenesis and novel pharmacotherapy of schizophrenia. Neurosignals 16:183-193.

Poo MM (2001) Neurotrophins as synaptic modulators. Nat Rev Neurosci 2:24-32.

Price RB, Nock MK, Charney DS, and Mathew SJ (2009) Effects of intravenous ketamine on explicit and implicit measures of suicidality in treatment-resistant depression. Biol Psychiatry 66:522-526.

Price RD, Milne SA, Sharkey J, and Matsuoka N (2007) Advances in small molecules promoting neurotrophic function. Pharmacol Ther 115:292-306.

Rantamäki T, Hendolin P, Kankaanpää A, Mijatovic J, Piepponen P, Domenici E, Chao MV, Männistö PT, and Castrén E (2007) Pharmacologically diverse antidepressants rapidly activate brain-derived neurotrophic factor receptor TrkB and induce phospholipase-Cgamma signaling pathways in mouse brain. Neuropsychopharmacology 32:2152-2162.

Rask-Andersen M, Olszewski PK, Levine AS, and Schiöth HB (2010) Molecular mechanisms underlying anorexia nervosa: focus on human gene association studies and systems controlling food intake. Brain Res Rev 62:147-164.

Rattiner LM, Davis M, French CT, and Ressler KJ (2004) Brain-derived neurotrophic factor and tyrosine kinase receptor B involvement in amygdala dependent fear conditioning. J Neurosci 24:4796-4806.

Regier DA, Narrow WE, Rae DS, Manderscheid RW, Locke BZ, and Goodwin FK (1993) The de facto US mental and addictive disorders service system. Epidemiologic catchment area prospective 1-year prevalence rates of disorders and services. Arch Gen Psychiatry 50:85-94.

Ribasés M, Gratacòs M, Fernández-Aranda F, Bellodi L, Boni C, Anderluh M, Cavallini MC, Cellini E, Di Bella D, Erzegovesi S, et al. (2004) Association of BDNF with anorexia, bulimia and age of onset of weight loss in six European populations. Hum Mol Genet 13:1205-1212.

Ribasés M, Gratacòs M, Fernández-Aranda F, Bellodi L, Boni C, Anderluh M, Cristina Cavallini M, Cellini E, Di Bella D, Erzegovesi S, et al. (2005) Association of BDNF with restricting anorexia nervosa and minimum body mass index: a family-based association study of eight European populations. Eur J Hum Genet 13:428-434

Richtand NM, Taylor B, Welge JA, Ahlbrand R, Ostrander MM, Burr J, Hayes S, Coolen LM, Pritchard LM, Logue A, et al. (2006) Risperidone pretreatment prevents elevated locomotor activity following neonatal hippocampal lesions. Neuro psychopharmacology 31:77-89.

Robinson TE and Kolb B (1999) Alterations in the morphology of dendrites and dendritic spines in the nucleus accumbens and prefrontal cortex following repeated treatment with amphetamine or cocaine. Eur J Neurosci 11:1598-1604.

Roelfsema JH and Peters DJ (2007) Rubinstein-Taybi syndrome: clinical and molecular overview. Expert Rev Mol Med 9:1-16.

Rose CR, Blum R, Kafitz KW, Kovalchuk Y, and Konnerth A (2004) From modulator to mediator: rapid effects of BDNF on ion channels. Bioessays 26:1185-1194.

Roux PP and Barker PA (2002) Neurotrophin signaling through the p75 neurotrophin receptor. Prog Neurobiol 67:203-233.

Rueter LE, Ballard ME, Gallagher KB, Basso AM, Curzon P, and Kohlhaas KL (2004) Chronic low dose risperidone and clozapine alleviate positive but not negative symptoms in the rat neonatal ventral hippocampal lesion model of schizophrenia. Psychopharmacology (Berl) 176:312-319.

Russo SJ, Mazei-Robison MS, Ables JL, and Nestler EJ (2009) Neurotrophic factors and structural plasticity in addiction. Neuropharmacology 56 (Suppl 1):73-82.

Rybakowski F, Dmitrzak-Weglarz M, Szczepankiewicz A, Skibinska M, Slopien A Rajewski A, and Hauser J (2007) Brain derived neurotrophic factor gene Val66Met and $-270 \mathrm{C} / \mathrm{T}$ polymorphisms and personality traits predisposing to anorexia nervosa. Neuro Endocrinol Lett 28:153-158.

Saarelainen T, Hendolin P, Lucas G, Koponen E, Sairanen M, MacDonald E, Ager man K, Haapasalo A, Nawa H, Aloyz R, et al. (2003) Activation of the TrkB neurotrophin receptor is induced by antidepressant drugs and is required for antidepressant-induced behavioral effects. J Neurosci 23:349-357.

Sanacora G (2008) New understanding of mechanisms of action of bipolar medications. J Clin Psychiatry 69 (Suppl 5):22-27.

Santarelli L, Saxe M, Gross C, Surget A, Battaglia F, Dulawa S, Weisstaub N, Lee 
J, Duman R, Arancio O, et al. (2003) Requirement of hippocampal neurogenesis for the behavioral effects of antidepressants. Science 301:805-809.

Saylor AJ and McGinty JF (2008) Amphetamine-induced locomotion and gene expression are altered in BDNF heterozygous mice. Genes Brain Behav 7:906-914. Schmitt KC and Reith ME (2010) Regulation of the dopamine transporter: aspects relevant to psychostimulant drugs of abuse. Ann N Y Acad Sci 1187:316-340.

Schuman EM (1999) Neurotrophin regulation of synaptic transmission. Curr Opin Neurobiol 9:105-109.

Seeman P (2002) Atypical antipsychotics: mechanism of action. Can J Psychiatry 47:27-38.

Sen S, Duman R, and Sanacora G (2008) Serum brain-derived neurotrophic factor, depression, and antidepressant medications: meta-analyses and implications. Biol Psychiatry 64:527-532.

Serres F and Carney SL (2006) Nicotine regulates SH-SY5Y neuroblastoma cell proliferation through the release of brain-derived neurotrophic factor. Brain Res 1101:36-42.

Shaltiel G, Chen G, and Manji HK (2007) Neurotrophic signaling cascades in the pathophysiology and treatment of bipolar disorder. Curr Opin Pharmacol 7:22-26 Shelton RC (2007) The molecular neurobiology of depression. Psychiatr Clin North Am 30:1-11.

Shieh PB, Hu SC, Bobb K, Timmusk T, and Ghosh A (1998) Identification of a signaling pathway involved in calcium regulation of BDNF expression. Neuron 20:727-740.

Shirayama Y, Chen AC, Nakagawa S, Russell DS, and Duman RS (2002) Brainderived neurotrophic factor produces antidepressant effects in behavioral models of depression. J Neurosci 22:3251-3261.

Sklair-Tavron L, Shi WX, Lane SB, Harris HW, Bunney BS, and Nestler EJ (1996) Chronic morphine induces visible changes in the morphology of mesolimbic dopamine neurons. Proc Natl Acad Sci USA 93:11202-11207.

Sklar P, Gabriel SB, McInnis MG, Bennett P, Lim YM, Tsan G, Schaffner S, Kiroy G, Jones I, Owen M, et al. (2002) Family-based association study of 76 candidate genes in bipolar disorder: BDNF is a potential risk locus. Brain-derived neutrophic factor. Mol Psychiatry 7:579-593.

Soliman F, Glatt CE, Bath KG, Levita L, Jones RM, Pattwell SS, Jing D, Tottenham N, Amso D, Somerville LH, et al. (2010) A genetic variant BDNF polymorphism alters extinction learning in both mouse and human. Science 327:863-866.

Steen RG, Mull C, McClure R, Hamer RM, and Lieberman JA (2006) Brain volume in first-episode schizophrenia: systematic review and meta-analysis of magnetic resonance imaging studies. Br J Psychiatry 188:510-518.

Sun D, Huang W, Hwang YY, Zhang Y, Zhang Q, and Li MD (2007) Regulation by nicotine of Gpr51 and Ntrk2 expression in various rat brain regions. Neuropsychopharmacology 32:110-116.

Szczepankiewicz A, Skibinska M, Czerski PM, Kapelski P, Leszczynska-Rodziewicz A, Słopien A, Dmitrzak-Weglarz M, Rybakowski F, Rybakowski J, and Hauser J (2005) No association of the brain-derived neurotrophic factor (BDNF) gene C-270T polymorphism with schizophrenia. Schizophr Res 76:187-193.

Szekeres G, Juhász A, Rimanóczy A, Kéri S, and Janka Z (2003) The C270T polymorphism of the brain-derived neurotrophic factor gene is associated with schizophrenia. Schizophr Res 65:15-18.

Tabuchi A, Sakaya H, Kisukeda T, Fushiki H, and Tsuda M (2002) Involvement of an upstream stimulatory factor as well as cAMP-responsive element-binding protein in the activation of brain-derived neurotrophic factor gene promoter I. J Biol Chem 277:35920-35931.

Takahashi M, Shirakawa O, Toyooka K, Kitamura N, Hashimoto T, Maeda K, Koizumi S, Wakabayashi K, Takahashi H, Someya T, et al. (2000) Abnormal expression of brain-derived neurotrophic factor and its receptor in the corticolimbic system of schizophrenic patients. Mol Psychiatry 5:293-300.

Tamminga CA and Holcomb HH (2005) Phenotype of schizophrenia: a review and formulation. Mol Psychiatry 10:27-39.

Tao X, Finkbeiner S, Arnold DB, Shaywitz AJ, and Greenberg ME (1998) Ca2+ influx regulates BDNF transcription by a CREB family transcription factordependent mechanism. Neuron 20:709-726.

Tardito D, Perez J, Tiraboschi E, Musazzi L, Racagni G, and Popoli M (2006) Signaling pathways regulating gene expression, neuroplasticity, and neurotrophic mechanisms in the action of antidepressants: a critical overview. Pharmacol Rev 58:115-134.

Tebartz van Elst L, Woermann F, Lemieux L, and Trimble MR (2000) Increased amygdala volumes in female and depressed humans. A quantitative magnetic resonance imaging study. Neurosci Lett 281:103-106.

Thompson Ray M, Weickert CS, Wyatt E, and Webster MJ (2011) Decreased BDNF, trkB-TK + and GAD67 mRNA expression in the hippocampus of individuals with schizophrenia and mood disorders. J Psychiatry Neurosci 36:195-203.

Thornton LM, Dellava JE, Root TL, Lichtenstein P, and Bulik CM (2011) Anorexia nervosa and generalized anxiety disorder: further explorations of the relation between anxiety and body mass index. J Anxiety Disord 25:727-730.

Tordjman S, Drapier D, Bonnot O, Graignic R, Fortes S, Cohen D, Millet B, Laurent C, and Roubertoux PL (2007) Animal models relevant to schizophrenia and autism: validity and limitations. Behav Genet 37:61-78.

Tseng KY, Chambers RA, and Lipska BK (2009) The neonatal ventral hippocampal lesion as a heuristic neurodevelopmental model of schizophrenia. Behav Brain Res 204:295-305.

Tyler WJ, Zhang XL, Hartman K, Winterer J, Muller W, Stanton PK, and PozzoMiller L (2006) BDNF increases release probability and the size of a rapidly recycling vesicle pool within rat hippocampal excitatory synapses. J Physiol 574: $787-803$

van Haren NE, Bakker SC, and Kahn RS (2008) Genes and structural brain imaging in schizophrenia. Curr Opin Psychiatry 21:161-167.

Volk DW, Austin MC, Pierri JN, Sampson AR, and Lewis DA (2000) Decreased glutamic acid decarboxylase67 messenger RNA expression in a subset of prefrontal cortical gamma-aminobutyric acid neurons in subjects with schizophrenia. Arch Gen Psychiatry 57:237-245.

Watanabe Y, Muratake T, Kaneko N, Nunokawa A, and Someya T (2006) No association between the brain-derived neurotrophic factor gene and schizophrenia in a Japanese population. Schizophr Res 84:29-35.

Watanabe Y, Nunokawa A, Kaneko N, and Someya T (2007) Meta-analysis of case-control association studies between the C270T polymorphism of the brainderived neurotrophic factor gene and schizophrenia. Schizophr Res 95:250-252.

Waterhouse EG and Xu B (2009) New insights into the role of brain-derived neurotrophic factor in synaptic plasticity. Mol Cell Neurosci 42:81-89.

Weickert CS, Hyde TM, Lipska BK, Herman MM, Weinberger DR, and Kleinman JE (2003) Reduced brain-derived neurotrophic factor in prefrontal cortex of patients with schizophrenia. Mol Psychiatry 8:592-610.

Willner P (2005) Chronic mild stress (CMS) revisited: consistency and behaviouralneurobiological concordance in the effects of CMS. Neuropsychobiology 52:90-110.

Wittert G, Hope P, and Pyle D (1996) Tissue distribution of opioid receptor gene expression in the rat. Biochem Biophys Res Commun 218:877-881.

Woo NH, Teng HK, Siao CJ, Chiaruttini C, Pang PT, Milner TA, Hempstead BL, and $\mathrm{Lu}$ B (2005) Activation of p75NTR by proBDNF facilitates hippocampal long-term depression. Nat Neurosci 8:1069-1077.

Xu MQ, St Clair D, Ott J, Feng GY, and He L (2007) Brain-derived neurotrophic factor gene C-270T and Val66Met functional polymorphisms and risk of schizophrenia: a moderate-scale population-based study and meta-analysis. Schizophr Res 91:6-13.

Yan HC, Cao X, Das M, Zhu XH, and Gao TM (2010) Behavioral animal models of depression. Neurosci Bull 26:327-337.

Yang J, Siao CJ, Nagappan G, Marinic T, Jing D, McGrath K, Chen ZY, Mark W, Tessarollo L, Lee FS, et al. (2009) Neuronal release of proBDNF. Nat Neurose 12:113-115.

Yang T, Yin W, Derevyanny VD, Moore LA, and Longo FM (2005) Identification of an ectodomain within the LAR protein tyrosine phosphatase receptor that binds homophilically and activates signalling pathways promoting neurite outgrowth Eur J Neurosci 22:2159-2170.

Yasui DH, Peddada S, Bieda MC, Vallero RO, Hogart A, Nagarajan RP, Thatcher KN, Farnham PJ, and Lasalle JM (2007) Integrated epigenomic analyses of neuronal MeCP2 reveal a role for long-range interaction with active genes. Proc Natl Acad Sci USA 104:19416-19421.

Yoshii A and Constantine-Paton M (2010) Postsynaptic BDNF-TrkB signaling in synapse maturation, plasticity, and disease. Dev Neurobiol 70:304-322.

$\mathrm{Yu} \mathrm{H}$ and Chen ZY (2011) The role of BDNF in depression on the basis of its location in the neural circuitry. Acta Pharmacol Sin 32:3-11.

Zarate CA, Jr., Singh JB, Carlson PJ, Brutsche NE, Ameli R, Luckenbaugh DA, Charney DS, and Manji HK (2006) A randomized trial of an $N$-methyl-D-aspartate antagonist in treatment-resistant major depression. Arch Gen Psychiatry 63:856864. 